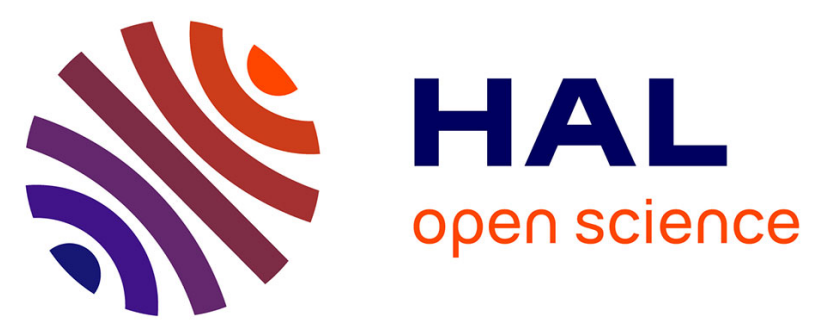

\title{
Glassy GaS: transparent and unusually rigid thin films for visible to mid-IR memory applications
}

Andrey Tverjanovich, Maxim Khomenko, Sergei Bereznev, Daniele Fontanari, Anton Sokolov, Takeshi Usuki, Koji Ohara, David Le Coq, Pascal Masselin, Eugène Bychkov

\section{To cite this version:}

Andrey Tverjanovich, Maxim Khomenko, Sergei Bereznev, Daniele Fontanari, Anton Sokolov, et al.. Glassy GaS: transparent and unusually rigid thin films for visible to mid-IR memory applications. Physical Chemistry Chemical Physics, 2020, 22 (44), pp.25560-25573. 10.1039/d0cp04697c . hal02999002

\section{HAL Id: hal-02999002 \\ https://hal.science/hal-02999002}

Submitted on 15 Dec 2020

HAL is a multi-disciplinary open access archive for the deposit and dissemination of scientific research documents, whether they are published or not. The documents may come from teaching and research institutions in France or abroad, or from public or private research centers.
L'archive ouverte pluridisciplinaire HAL, est destinée au dépôt et à la diffusion de documents scientifiques de niveau recherche, publiés ou non, émanant des établissements d'enseignement et de recherche français ou étrangers, des laboratoires publics ou privés. 


\title{
Glassy GaS: transparent and unusually rigid thin films for visible to mid-IR memory applications
}

Andrey Tverjanovich, ${ }^{a}$ Maxim Khomenko, ${ }^{b}$ Sergei Bereznev, ${ }^{c}$ Daniele Fontanari, ${ }^{d}$ Anton Sokolov,${ }^{b, d}$ Takeshi Usuki, ${ }^{e}$ Koji Ohara,$f$ David Le Coq,${ }^{g}$ Pascal Masselin, ${ }^{d}$ and Eugene Bychkov ${ }^{b, d *}$

${ }^{a}$ Institute of Chemistry, St. Petersburg State University, 198504 St. Petersburg, Russia

${ }^{b}$ ILIT RAS - Branch of the FSRC 'Crystallography and Photonics' RAS, 140700 Shatura, Moscow Region, Russia

${ }^{c}$ Department of Materials and Environmental Technology, Tallinn University of Technology, 19086 Tallinn, Estonia

${ }^{d}$ Laboratoire de Physico-Chimie de l'Atmosphère, Université du Littoral Côte d'Opale, 59140 Dunkerque,

France

e Faculty of Science, Yamagata University, Yamagata 990-8560, Japan

f Diffraction and Scattering Division, Japan Synchrotron Radiation Research Institute, Sayo-gun, Hyogo 6795198, Japan

g Institut des Sciences Chimiques de Rennes, Université Rennes, 35000 Rennes, France

\begin{abstract}
Phase-change materials based on tellurides are widely used for optical storage (DVD and Blu-ray disks), non-volatile random access memories and for development of neuromorphic computing. Narrow-gap tellurides are intrinsically limited in the telecom spectral window, where materials having a wider gap are needed. Here we show that gallium sulfide GaS thin films prepared by pulsed laser deposition reveal a good transparency from visible to mid-IR spectral range with the optical gap $E_{\mathrm{g}}=2.34 \mathrm{eV}$, high refractive index $n_{\mathrm{R}}=2.50$ over the $0.8 \leq \lambda \leq 2.5 \mu \mathrm{m}$ range and, unlike to canonical chalcogenide glasses, the absence of photo-structural transformations with a laser-induced peak power density damage threshold above $1.4 \mathrm{TW} \mathrm{cm}^{-2}$ at $780 \mathrm{~nm}$. The origin of the excellent damage threshold to a high-power laser and UV light irradiation resides in rigid tetrahedral structure of vitreous GaS studied by high-energy X-ray diffraction, Raman spectroscopy and supported by first-principles simulations. The average local coordination number appears to be $\langle m\rangle=3.44$, well above the optimal connectivity, $2.4 \leq\langle m\rangle \leq 2.7$, and the total volume of microscopic voids and cavities is $34.4 \%$, that is, lower than for a vast majority of binary sulfide glasses. Glass-crystal phase transition in gallium sulfide thin films may be accompanied by a drastic change in nonlinear optical properties opening up a new dimension for memory applications in visible to mid-IR spectral ranges.
\end{abstract}

* Corresponding author. E-mail: bychkov@univ-littoral.fr 


\section{Introduction}

Phase-change materials (PCMs) based on tellurides (GeTe-Sb $\mathrm{Te}_{3}$, metal-doped $\mathrm{Sb}_{2} \mathrm{Te}$, etc.) are widely used for optical storage (DVD and Blu-ray disks), non-volatile random access memories and for development of bioinspired computing systems. ${ }^{1-5}$ High optical absorption of the narrow-gap tellurides below $\lambda=2 \mu \mathrm{m}$ intrinsically limits their applications in the telecom spectral range, where wider gap materials are needed. Recent studies of $\mathrm{Sb}_{2} \mathrm{~S}_{3}$ and related sulfides have shown a growing interest toward visible to mid-IR optical memory applications.6,7 Gallium sulfides, GaS and $\mathrm{Ga}_{2} \mathrm{~S}_{3}$, are promising materials in this field because a glass-crystal phase transition might be accompanied by a drastic change in nonlinear optical (NLO) properties, opening up a new dimension in the PCM photonics.

Gallium sesquisulfide $\mathrm{Ga}_{2} \mathrm{~S}_{3}$ in bulk chalcogenide glasses promotes dissolution of rare earth ions in the glass matrix ${ }^{8,9}$ allowing further development of optically active materials (bulk, planar and fibers).10,11 Monoclinic and cubic $\mathrm{Ga}_{2} \mathrm{~S}_{3}$ also exhibit excellent laser-induced damage threshold, 174 and $590 \mathrm{MW} \mathrm{cm}^{-2}$ at $1064 \mathrm{~nm}$, respectively, vs. $5.58 \mathrm{MW} \mathrm{cm}^{-2}$ in tetragonal $\mathrm{AgGaS}_{2} ;^{12}$ the silver thiogallate is a commercially available NLO crystal served as a light conversion reference in the mid-IR spectral range. Simultaneously, monoclinic $\mathrm{Ga}_{2} \mathrm{~S}_{3}$ shows a strong phase-matchable second harmonic generation (SHG). ${ }^{12}$ Hexagonal $\beta$-GaS has centrosymmetric structure, space group $P 6_{3} / m m c, 13$ and cannot possess the second order NLO properties. Nevertheless, native GaS crystals reveal the existence of non-centrosymmetric rhombohedral GaS domains and exhibit rather intense SHG. Pure rhombohedral GaS, space group $R \overline{3} m,{ }^{14}$ shows a strong second order response. ${ }^{15}$ In contrast, gallium sulfide bulk glasses exhibit a large and ultrafast thirdorder nonlinear susceptibility ${ }^{16,17}$ suggesting a dramatic crossover in NLO properties on crystallization.

Both $\mathrm{GaS}$ and $\mathrm{Ga}_{2} \mathrm{~S}_{3}$ are extensively studied in bulk and thin film forms.18-25 Nevertheless, the structure, composition and properties of amorphous gallium sulfide thin films are far from a full understanding and often contradictory. For example, the band gap of amorphous GaS obtained by thermal evaporation was found to be $E_{\mathrm{g}} \approx 1.1 \mathrm{eV},{ }^{18}$ while crystalline GaS shows $E_{\mathrm{g}}=2.50 \mathrm{eV}$ at room temperature. ${ }^{26} \mathrm{X}$-ray diffraction and EXAFS results at the Ga K-edge for amorphous $\mathrm{Ga}_{2} \mathrm{~S}_{3}$ thin films were reported to reveal trigonal gallium and two-fold sulfur local coordination. ${ }^{23}$ In contrast, crystalline gallium sulfides and gallium in bulk $\mathrm{Ga}_{2} \mathrm{~S}_{3}-\mathrm{GeS}_{2}$ sulfide glasses exhibit tetrahedral Ga environment. ${ }^{13,14,27-30}$ Often, the chemical composition of gallium sulfide thin films depends on deposition technique and technical details, ${ }^{25}$ leaving room for uncertainty in the relationships between nominal composition, suggested structure and observed properties.

The main objective of the present study was (i) to obtain high-quality gallium sulfide thin films using pulsed laser deposition and verify their chemical composition, (ii) to study the optical properties including fundamental absorption edge, refractive index and laser-induced damage threshold, and (iii) to elucidate their atomic structure using Raman and high-energy X-ray diffraction measurements supported by first-principles molecular dynamics simulations. A deep insight into molecular architecture of vitreous gallium sulfide layers in relation with their macroscopic characteristics will be crucial in the assessment of the required potential for memory applications over visible to mid-IR spectral ranges. 


\section{Experimental and simulation details}

\subsection{Material preparation}

Gallium sesquisulfide $\mathrm{Ga}_{2} \mathrm{~S}_{3}$ powder was synthesized from pure gallium (99.999\%, Alfa Aesar) and sulfur (99.999\%, Sterm) by mechanical milling. The two elements were placed in stoichiometric proportion (the total mass of $8 \mathrm{~g}$ ) into a tungsten carbide WC vessel (the internal volume of $45 \mathrm{~mL}$ ) with $10 \mathrm{WC}$ balls (10 $\mathrm{mm}$ in diameter) meaning a mass ratio balls/powder was 10:1. The mechanochemical processing was operated in a planetary ball mill (Fritsch, Pulverisette 7) for $4 \mathrm{~h}$ at a rotation speed of $400 \mathrm{rpm}$ in dry $\mathrm{N}_{2}$ atmosphere. The amorphous powder was collected, and the target (16 $\mathrm{mm}$ in diameter and $4 \mathrm{~mm}$ in thickness) was prepared by spark plasma sintering process at $700 \mathrm{~K}$ and $50 \mathrm{MPa}$ for $5 \mathrm{~min}$.

Pulsed laser deposition (PLD) of gallium sulfide films was performed by Neocera Pioneer 120 PLD system equipped with $248 \mathrm{~nm}$ KrF excimer laser (Coherent Compex Pro 102 F) under high vacuum. The target to substrate distance was $9 \mathrm{~cm}$. The conditions of the deposition were as follows: 40,000 laser pulses, $200 \mathrm{~mJ}$ pulse energy, $10 \mathrm{~Hz}$ repetition rate. The laser beam was focused on $\sim 5 \mathrm{~mm}^{2}$ spot on the surface of the target. The substrate and target were rotated during the deposition process for uniform distribution of the ablated materials onto the substrate of ambient temperature. Before PLD, soda lime glass substrates, $5 \mathrm{~cm}$ in diameter, were ultrasonically cleaned for $15 \mathrm{~min}$ in $20 \%$ solution of Decon 90 and deionized water at 323 $\mathrm{K}$, respectively, dried under filtered air flow and then exposed to Nova Scan Digital UV-Ozone cleaning system for $15 \mathrm{~min}$.

\subsection{Thin film characterization, optical and Raman spectroscopy measurements}

Gallium sulfide PLD layer morphology and chemical composition were characterized by scanning electron microscopy using a Zeiss EVO 40EB instrument equipped with EDX microanalysis system Oxford Instrument INCA 350. A Shimadzu UV-3600 spectrophotometer was used for optical absorption spectra measurements in the wavelength range of 300$2400 \mathrm{~nm}$. Raman spectra were measured at room temperature in backscattering geometry using a Senterra Raman spectrometer (Bruker) equipped with a microscope. The spectra were excited by a $785 \mathrm{~nm}$ laser with power $10 \mathrm{~mW}$ and recorded in the $75-1500 \mathrm{~cm}^{-1}$ spectral range (reliable data are above $100 \mathrm{~cm}^{-1}$ ). The spectrometer resolution was $3 \mathrm{~cm}^{-1}$. Additionally, some samples were measured using a LabRam HR microRaman spectrometer (Jobin Yvon Horiba Group). Raman scattering was excited by a $785 \mathrm{~nm}$ solid-state laser and recorded in the $50-850 \mathrm{~cm}^{-1}$ spectral range. The laser power was $1.5 \mathrm{~mW}$ in the majority of measurements, and the acquisition time was 100 to $300 \mathrm{~s}$. Two to three spectra were registered for each sample at different positions to verify the sample homogeneity and the absence of photo-induced phenomena.

A femtosecond laser Mira Optima 900-D (Coherent) with acousto-optic modulator Pulse Switch in cavity dumping operation mode was used to study a laser-induced high-power density damage threshold at $790 \mathrm{~nm}$. The pulse frequency was $272 \mathrm{kHz}$, and the pulse duration was 100 fs. The beam energy on the samples was about $10 \mathrm{~nJ}$. A gallium sulfide layer sensitivity to UV irradiation was studied using a $250 \mathrm{~W}$ mercury lamp. 


\subsection{Diffraction measurements}

Tiny pieces of gallium sulfide thin film material were placed into thin-walled silica capillary for high-energy X-ray diffraction measurements, Figure S1 in Electronic Supplementary Information (ESI). A dedicated two-axis diffractometer at the BL04B2 beamline of the SPring-8 facility (Hyogo Prefecture, Japan) equipped with four CdTe detectors at low angles and three Ge diodes at high diffraction angles ${ }^{31}$ was used for these measurements. The 7-detector setup allows the diffraction pattern to be collected up to $Q=30 \AA^{-1}$ with high signal-to noise ratio and sufficient energy resolution to discriminate both fluorescence from the sample and higher harmonics reflections from the monochromator crystal. The empty silica tube was also measured and used for background intensity subtraction. Further data analysis included absorption, Compton scattering, and polarization corrections using standard procedures ${ }^{32}$ giving the total X-ray structure factor $S_{\mathrm{X}}(Q)$.

\section{$2.4 \quad$ First-principles simulations}

Modeling of the high-energy X-ray diffraction data was carried out using the Born-Oppenheimer molecular dynamics with the $\mathrm{CP} 2 \mathrm{~K}$ package. ${ }^{33}$ The generalized gradient approximation and the PBEsol ${ }^{34,35}$ or PBE0 hybrid ${ }^{36,37}$ exchange-correlation functionals have been used. The applied first-principle molecular dynamics (FPMD) technique was similar to that used previously.38,39 The initial atomic configurations for glassy gallium sulfide were created and optimized using the RMC_POT++ code ${ }^{40,41}$ against the derived X-ray structure factor $S_{\mathrm{X}}(Q)$ in order to obtain a good agreement with experimental data. The size of the cubic simulation box at room temperature, containing 200 atoms (100 Ga and $100 \mathrm{~S}$ ), was chosen to match the experimental number density. Further optimization has been carried using density functional theory (DFT), applying the molecularly optimized correlation consistent polarized triple-zeta valence basis set TZVP 42,43 along with the norm-conserving relativistic Goedecker-Teter-Hutter type pseudo-potentials..$^{44,45}$ The FPMD simulations were started at $300 \mathrm{~K}$. In order to deal with a canonical NVT ensemble, a Nosé-Hoover ${ }^{46,47}$ chain of length 3 has been employed as a thermostat. The PBEsol or PBE0 systems were heated up to $700-1300 \mathrm{~K}$ using $100 \mathrm{~K}$ steps for 10 to 30 ps each. At 700,800 or $1300 \mathrm{~K}$, the systems were equilibrated for $20-35$ ps and cooled down to $300 \mathrm{~K}$ using the same temperature steps and similar simulation time. Final equilibration and data collection at $300 \mathrm{~K}$ was done for $25-45$ ps. The connectivity and ring statistics were analyzed using the R.I.N.G.S.48 and modified connectivity ${ }^{49}$ codes. For analysis of voids and cavities, the pyMolDyn ${ }^{50}$ program was used.

\section{$3 \quad$ Results and discussion}

\subsection{Chemical composition, Raman spectra and optical properties}

The pulsed laser deposition yields transparent, uniform and vitreous gallium sulfide layers, Fig. 1. The cross-sectional view shows a smooth vitreous layer of $3.5-4.0 \mu \mathrm{m}$ in thickness. The surface topography is uniform revealed by a secondary electron image. Finally, the obtained films are transparent from visible to mid-IR spectral window, $0.53 \leq \lambda \leq 12 \mu \mathrm{m}$. 


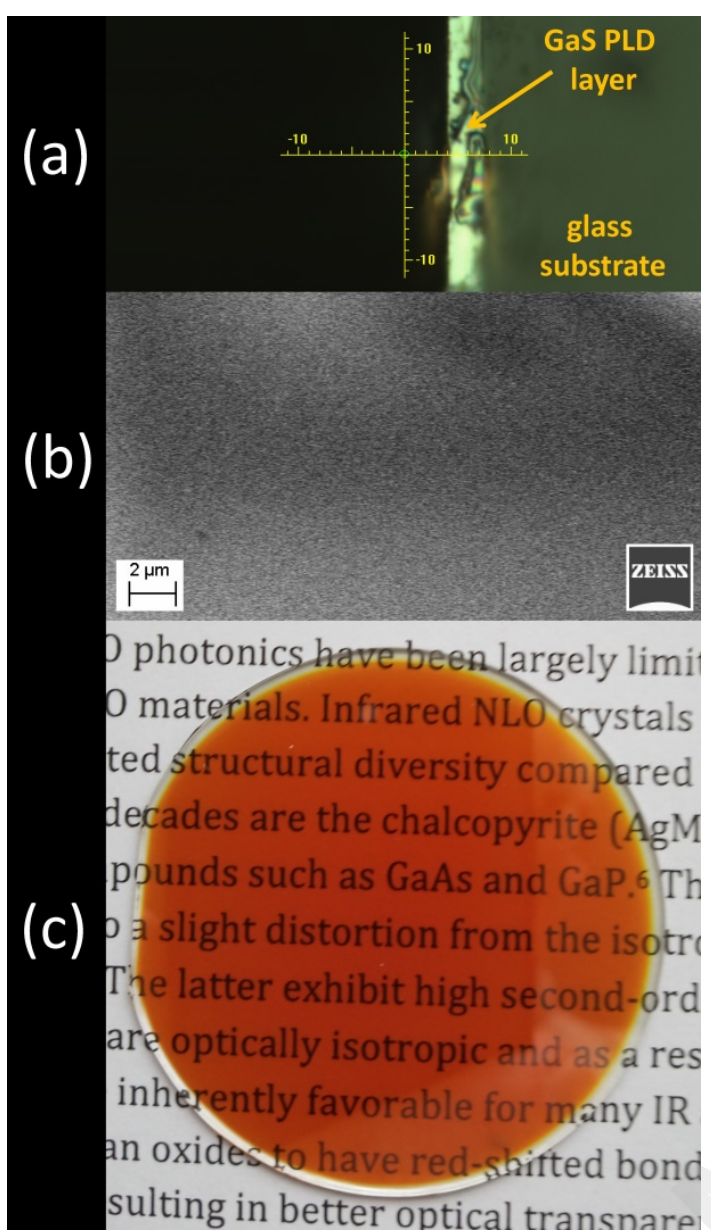

Fig. 1. GaS layer obtained by PLD: (a) crosssectional view revealing a 3.5-4 $\mu \mathrm{m}$ thick vitreous GaS layer and soda lime glass substrate, (b) layer surface image in secondary electrons, and (c) the entire transparent GaS film on glass substrate.

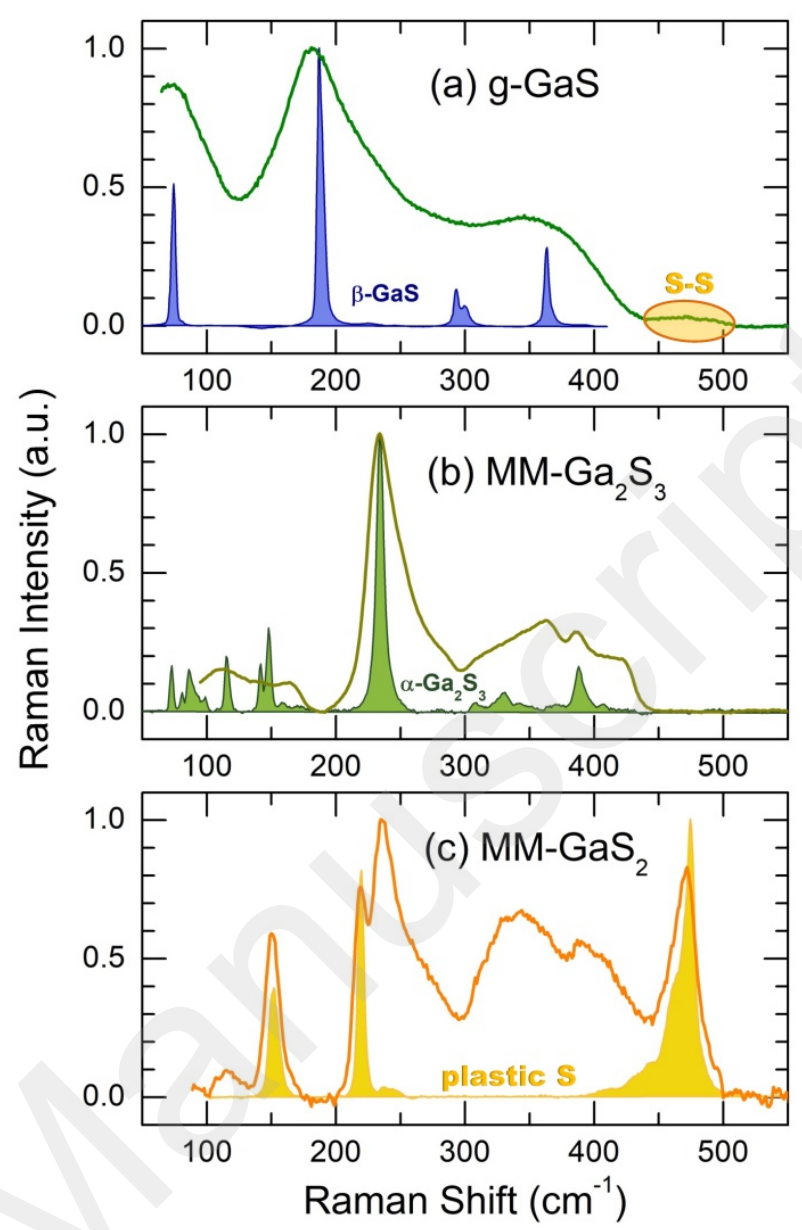

Fig. 2. Raman spectra of (a) GaS PLD layer, (b) MM$\mathrm{Ga}_{2} \mathrm{~S}_{3}$ and (c) $\mathrm{MM}-\mathrm{GaS}_{2}$, plotted together with crystalline references: (a) $\beta-G a S,{ }^{51}$ (b) $\alpha-\mathrm{Ga}_{2} \mathrm{~S}_{3}$, and (c) plastic sulfur. The S-S stretching vibrations in gGaS are highlighted in yellow.

Unexpected result was given by EDX chemical analysis. The film composition was found to be $\mathrm{Ga}_{53 \pm 2} \mathrm{~S}_{47 \pm 2}$, that is, close to stoichiometric monosulfide $\mathrm{GaS}$ instead of $\mathrm{Ga}_{2} \mathrm{~S}_{3}$. The Raman spectra of gallium sulfide PLD films are consistent with that conclusion. Figure 2 summarizes the measured Raman spectra of GaS PLD layer, semi-crystalline $\mathrm{MM}-\mathrm{Ga}_{2} \mathrm{~S}_{3}$ and $\mathrm{MM}-\mathrm{GaS}_{2}$, obtained by mechanical milling (MM) and plotted together with crystalline references: hexagonal $\beta-G a S, 51$ monoclinic $\alpha-\mathrm{Ga}_{2} \mathrm{~S}_{3}$, and (c) plastic sulfur. We note that the most intense vibrational feature of vitreous PLD film at $183 \mathrm{~cm}^{-1}$ is similar to the $A_{1 \mathrm{~g}}$ symmetric in-phase Ga-Ga stretching mode in $\beta$-GaS, $189 \mathrm{~cm}^{-1} .51,52$ The $183 \mathrm{~cm}^{-1}$ peak position is markedly lower than the $A^{\prime}$ in-phase Ga-S breathing of $\mathrm{GaS}_{4}$ tetrahedra of $C_{\mathrm{s}}$ symmetry in $\alpha-\mathrm{Ga}_{2} \mathrm{~S}_{3}$ at $233 \mathrm{~cm}^{-1.53}$ In contrast, the most intense vibrational feature of semi-crystalline $\mathrm{MM}-\mathrm{Ga}_{2} \mathrm{~S}_{3}$ is perfectly consistent with the $A^{\prime}$ mode, Fig. 2(b). High-frequency Ga-S stretching modes in $\beta-G a S, 290 \leq \omega \leq 360 \mathrm{~cm}^{-1}$, are also very similar to broad unresolved peaks in glassy GaS in this frequency range, as well as the intense $E_{1 \mathrm{~g}}$ bending vibrations at $\approx 76 \mathrm{~cm}^{-1}$. We also note a broad and weak feature at $\approx 475 \mathrm{~cm}^{-1}$, specific only of g-GaS. Vibrational modes in this range usually belong to S-S stretching as shows a typical Raman spectrum of sulfur-rich MM-GaS 2 , Fig. 2(c). The excessive sulfur in MM-GaS $\mathrm{S}_{2}$ exists as a plastic $S$ allotrope, ${ }^{54}$ characterized by strong bending and S-S stretching modes at 150, 220 and $475 \mathrm{~cm}^{-1}$, respectively. One can hardly imagine the presence of plastic sulfur in vitreous sulfurpoor GaS. Nevertheless, a small concentration of S-S dimers seems to be realistic. 
The observed composition difference between the $\mathrm{Ga}_{2} \mathrm{~S}_{3}$ target and gallium sulfide PLD layers may have various origins. First, stoichiometric $\mathrm{Ga}_{2} \mathrm{~S}_{3}$ at high temperatures transforms into nonstoichiometric sulfides $\mathrm{Ga}_{4} \mathrm{~S}_{x}$, where $4.8 \leq x \leq 5.2 .55$ This disproportionation should occur mostly during thermal evaporation. In addition, the vapor phase above $\mathrm{Ga}_{2} \mathrm{~S}_{3}$ essentially consists of $\mathrm{Ga}_{2} \mathrm{~S}$ and $\mathrm{S}_{2}$ stable molecules instead of molecular fragments $\mathrm{Ga}_{2} \mathrm{~S}_{3 .}{ }^{56}$ Finally, the laser ablation of solid $\mathrm{Ga}_{2} \mathrm{~S}_{3}$ generates the dominant atomic species ${ }^{32} \mathrm{~S}^{+},{ }^{34} \mathrm{~S}^{+},{ }^{69} \mathrm{Ga}^{+}$, and ${ }^{71} \mathrm{Ga}^{+}$, while the molecular clusters $\mathrm{Ga}_{m} \mathrm{~S}_{n}^{+}$, where $2 \leq m, n \leq 6$, represent the minority species. ${ }^{57}$ The observed effect can also be attributed to the evaporation of $S$ during the deposition process under high dynamic vacuum, $\approx 3 \times 10^{-6}$ Torr, before the nucleation stage on the substrate surface. 58
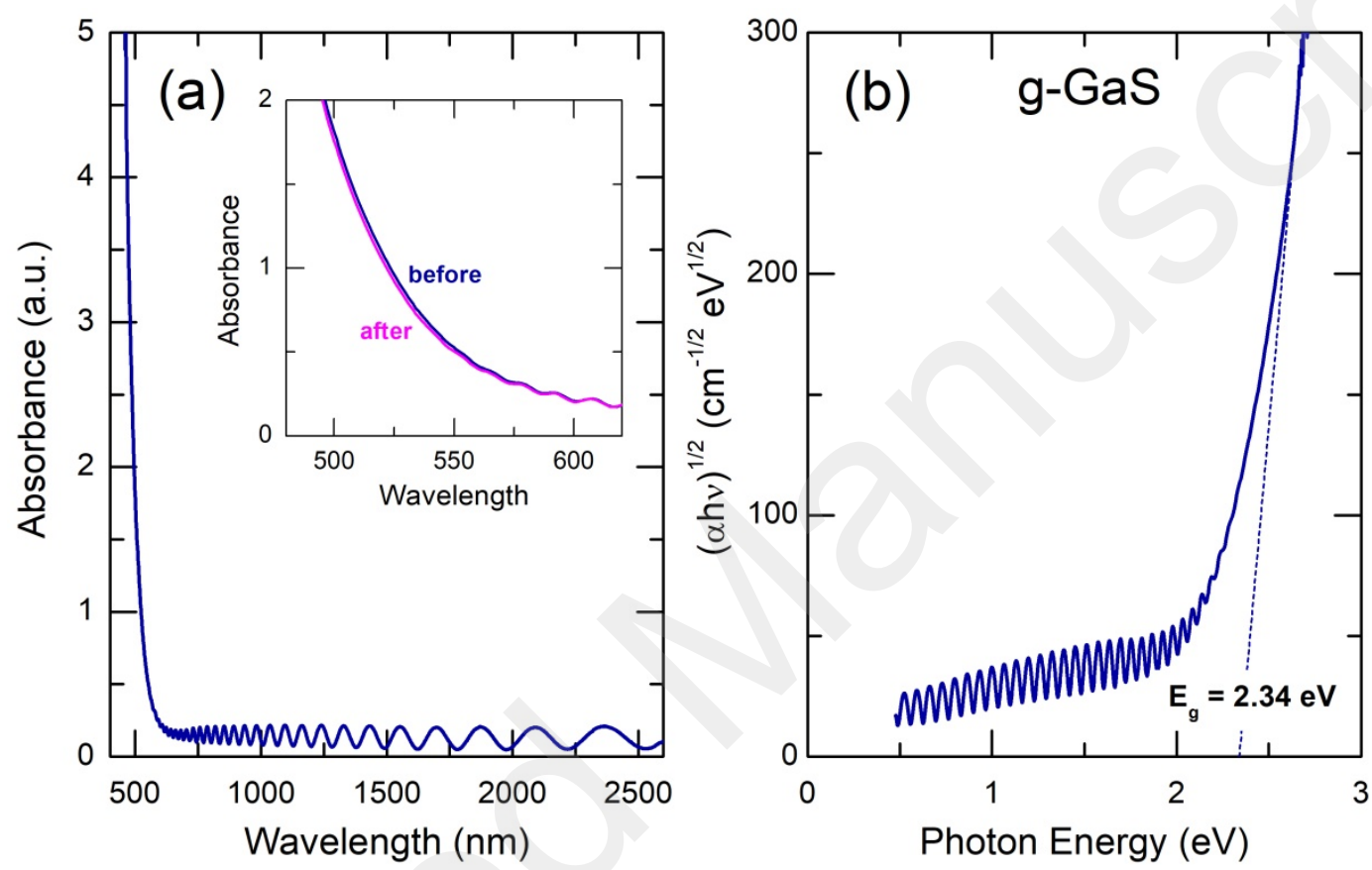

Fig. 3. Optical characteristics of GaS PLD layers: (a) absorption spectrum of the film with interference fringes, the inset shows a negligible difference in optical absorption between the virgin layer (blue) and that irradiated with a $250 \mathrm{~W}$ mercury lamp for $65 \mathrm{~min}$ (magenta); (b) optical band gap $E_{\mathrm{g}}$ determination.

The transparency of the GaS PLD layer and its uniformity were confirmed by optical absorption measurements with distinct interference fringes, Fig. 3(a). Using the Swanepoel technique, ${ }^{59}$ the layer thickness $d$ and the refractive index $n_{\mathrm{R}}$ over the $0.8 \leq \lambda \leq 2.5 \mu \mathrm{m}$ spectral range were calculated from the transmission spectrum derived from absorption. The calculated thickness $d$ $=3.8 \pm 0.2 \mu \mathrm{m}$ was consistent with that observed visually, Fig. 1(a). The refractive index $n_{\mathrm{R}}=$ $2.50 \pm 0.01$, derived using the substrate refractive index $n_{\mathrm{S}}=1.58$, was similar to that of crystalline $\mathrm{GaS}^{15}$ and higher than for majority of sulfide glasses. ${ }^{60,61}$

The fundamental absorption range of chalcogenide glasses is described by the following equation 62

$\alpha=\frac{A\left(h v-E_{\mathrm{g}}\right)^{k}}{h v}$

where $\alpha>10^{4} \mathrm{~cm}^{-1}$ is the absorption coefficient, $E_{\mathrm{g}}$ the optical band gap, $h v$ the incident photon energy, $k$ is the parameter, characterizing the optical transition between the valence and 
conduction bands ( $k=2$ for most chalcogenide glasses), 62 and $A \approx 10^{5} \mathrm{~cm}^{-1} \mathrm{eV}^{-1}$ is a constant. The experimental absorption data for glassy GaS layer are well described by Eq. (1), Fig. 3(b). The derived optical band gap $E_{\mathrm{g}}=2.34 \mathrm{eV}$ is very similar to that for crystalline $\mathrm{GaS}, 2.50 \mathrm{eV}$, 26 and remarkably lower than $E_{\mathrm{g}}$ for $\mathrm{Ga}_{2} \mathrm{~S}_{3}$ polymorphs, $2.74 \mathrm{eV} \leq E_{\mathrm{g}} \leq 3.30 \mathrm{eV} \cdot{ }^{63-65}$

A characteristic feature of chalcogenide glass thin films is their ability to change optical, structural and chemical properties under light irradiation with photon energy close to $E_{\mathrm{g}} \cdot{ }^{66} \mathrm{~A}$ shift of the fundamental absorption edge, a change of the optical constants or different etching rates in alkaline solutions are only few examples of photo-structural transformations, used for photolithographic processes, creation of diffraction gratings, Bragg reflectors, etc. The initial properties can be recovered after annealing in the vicinity of the glass transition temperature $T_{\mathrm{g}}$. The photo-structural transformations have also negative consequences. Typical chalcogenide glasses like $\mathrm{As}_{2} \mathrm{~S}_{3}$ cannot transmit a high-power light because of photoinduced changes.

In contrast to this typical behavior, the obtained GaS PLD layers appear to be extremely stable to high-intensity UV light. A $250 \mathrm{~W}$ mercury lamp irradiation for 65 minutes does not change the spectral position of the fundamental absorption edge, see the inset in Fig. 3(a). No photoinduced changes were observed using a femtosecond laser irradiation at the wavelength $\lambda=780$ $\mathrm{nm}$. The laser-induced peak power density damage threshold was found to be above $\approx 1.4 \mathrm{TW}$ $\mathrm{cm}^{-2}$. For comparison, the permanent changes of the refractive index for $\mathrm{CsCl}_{-} \mathrm{Ga}_{2} \mathrm{~S}_{3}-\mathrm{GeS}_{2}$ glasses occur above $62 \mathrm{GW} \mathrm{cm}^{-2}$ at $800 \mathrm{~nm},{ }^{67}$ as well as for other chalcogenide glasses. ${ }^{68}$

A high-power laser-induced damage threshold for vitreous gallium sulfide PLD layers is crucial for NLO-related applications. Typically, isotropic chalcogenide glasses are optically highly nonlinear. ${ }^{69}$ The nonlinear optical susceptibility of the third order $\chi^{3}$ is mainly defined by the refractive index $n_{\mathrm{R}}$ according to simplified expression ${ }^{70}$

$\chi^{3} \cong \frac{B\left(n_{\mathrm{R}}^{2}-1\right)^{4}}{(4 \pi)^{4}}$,

where $B \approx 1.7 \times 10^{-10}$ esu is a constant. Chalcogenide glasses with high $n_{\mathrm{R}}$ values exhibit the $\chi^{3}$ susceptibility by two orders of magnitude larger than oxide glass systems and appear to be attractive materials for all-optical ultrafast switches, frequency converters, electro-optic modulators, etc. ${ }^{69}$ However, the third-order NLO generation needs propagation of a high power light, limited in glassy chalcogenides by photo-structural transformations and respective changes of the optical constants. ${ }^{71}$

Consequently, the obtained gallium sulfide PLD layers have three promising features: (1) the refractive index $n_{\mathrm{R}}=2.50$ is higher than in usual sulfide glasses, e.g. the Ge-S glass system is characterized by $2.0 \leq n_{\mathrm{R}} \leq 2.1 ;{ }^{72}$ (2) the high-power laser-induced damage threshold allowing high-intensity NLO applications, and (3) the good optical transparency from visible to mid-IR spectral range.

The question arises what is the structural basis of these features. Going in opposite direction, the photo-structural transformations are promoted by (a) two-fold coordinated chalcogen species ( $\mathrm{S}, \mathrm{Se}, \mathrm{Te}$ ) providing flexible network structure, and (b) sufficient free volume, that is, a large number of voids and cavities delivering enough space for atomic mobility. ${ }^{66}$ The structural studies supported by first-principles simulations are expected to give some answers. 


\subsection{High-energy X-ray diffraction}

The X-ray structure factor $S_{\mathrm{X}}(Q)$ of the obtained PLD gallium sulfide layer is shown in Fig. 4

$S_{\mathrm{X}}(Q)=w_{\mathrm{GaGa}}(Q) S_{\mathrm{GaGa}}(Q)+w_{\mathrm{GaS}}(Q) S_{\mathrm{GaS}}(Q)+w_{\mathrm{SS}}(Q) S_{\mathrm{SS}}(Q)$,

where $w_{\mathrm{ij}}(Q)$ are $Q$-dependent X-ray weighting coefficients and $S_{\mathrm{ij}}(Q)$ the Faber-Ziman partial structure factors. The sample is fully amorphous without any crystalline impurities. The first sharp diffraction peak (FSDP) at $Q_{0}=1.03 \AA^{-1}$ is small in comparison with both $\mathrm{Ga}_{2} \mathrm{~S}_{3}-\mathrm{GeS}_{2}$ glasses and semi-crystalline $\mathrm{MM}-\mathrm{Ga}_{2} \mathrm{~S}_{3}$, prepared by mechanical milling, see the inset in Fig. 4 . The amplitude of high- $Q$ oscillations $\left(Q>12 \AA^{-1}\right)$ is also remarkably smaller vis-à-vis MM- $\mathrm{Ga}_{2} \mathrm{~S}_{3}$ and $g-\left(\mathrm{Ga}_{2} \mathrm{~S}_{3}\right)_{0.3}\left(\mathrm{GeS}_{2}\right)_{0.7}$. Similar trend was observed for $(\mathrm{GeS})_{x}\left(\mathrm{GeS}_{2}\right)_{1-x}$ glasses with increasing GeS content $x .{ }^{73}$

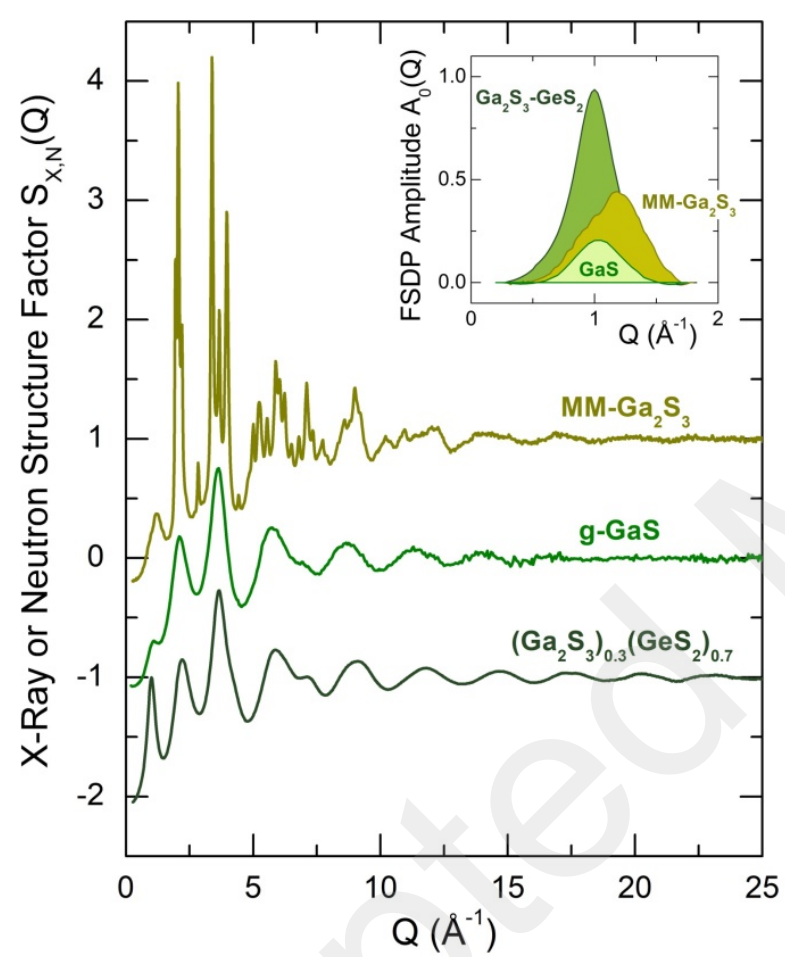

Fig. 4. X-ray $S_{\mathrm{X}}(Q)$ or neutron $S_{\mathrm{N}}(Q)$ structure factors for $\mathrm{MM}_{-} \mathrm{Ga}_{2} \mathrm{~S}_{3}$ (neutrons), glassy $\mathrm{GaS}$ and $\left(\mathrm{Ga}_{2} \mathrm{~S}_{3}\right)_{0.3}\left(\mathrm{GeS}_{2}\right)_{0.7}$ (X-rays). The inset shows isolated FSDP for these samples derived using a previously reported ${ }^{74,75}$ subtraction procedure.

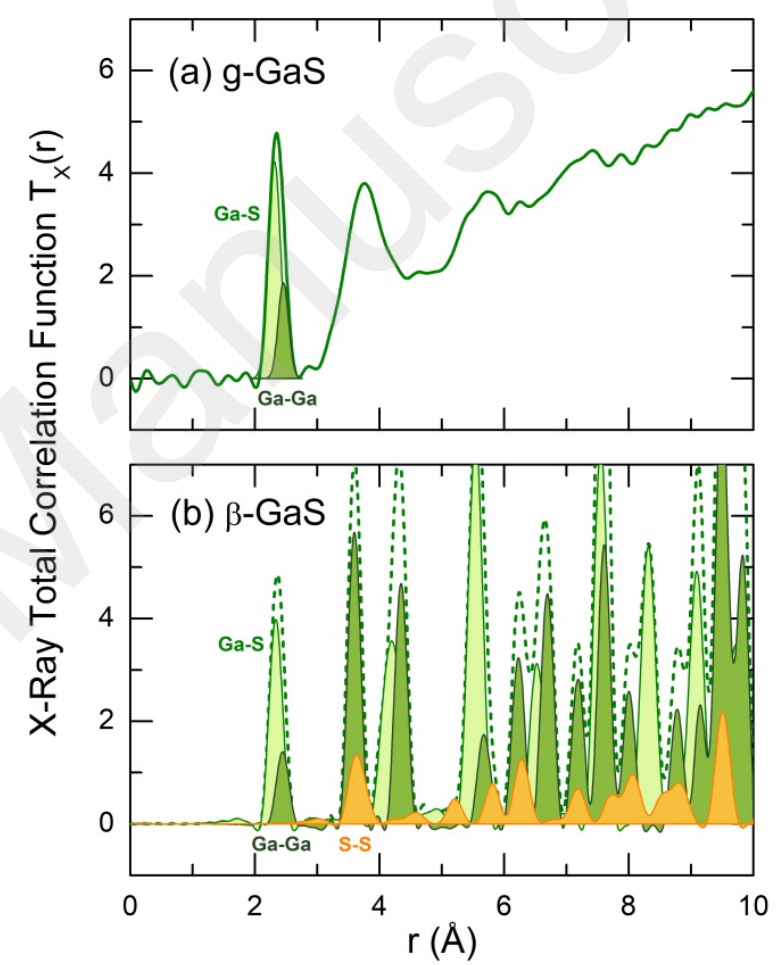

Fig. 5. X-ray total correlation functions $T_{\mathrm{X}}(r)$ for (a) glassy GaS, and (b) hexagonal polymorph $\beta$ GaS, space group $P 6_{3} / m m c{ }^{13}$ The Ga-S, Ga-Ga and S-S partials are highlighted in light green, green, and yellow, respectively.

The total correlation function $T_{\mathrm{X}}(r)$ of g-GaS, derived through the usual Fourier transform, is shown in Fig. 5

$T_{\mathrm{X}}(r)=4 \pi \rho_{0} r+\frac{2}{\pi} \int_{0}^{Q_{\max }} Q\left[S_{\mathrm{X}}(Q)-1\right] \sin Q r M(Q) \mathrm{d} Q$,

where $M(Q)$ is the Lorch window function, ${ }^{76} \rho_{0}$ the number density and $Q_{\max }=25 \AA^{-1}$. The asymmetric peak at $\approx 2.35 \AA$ suggests a mixed gallium local environment similar to that in crystalline GaS polymorphs, ${ }^{13,14,77}$ Fig. 5(b). A Gaussian peak fitting allows the two contributions to be identified: (i) the Ga-S nearest neighbors (NN) at $2.31 \pm 0.01 \AA$, the partial coordination number $N_{\mathrm{GaS}}=2.92 \pm 0.03$; and (ii) the Ga-Ga NN at $2.46 \pm 0.01 \AA, N_{\mathrm{GaGa}}=0.96 \pm 0.05$. The derived 
parameters are similar to those in hexagonal GaS: (i) $2.332 \AA, N_{\mathrm{GaS}}=3$; and (ii) $2.449 \AA$, $N_{\mathrm{GaGa}}=$ 1.13

The position and shape of a broad unresolved second neighbor peak at $\approx 3.75 \AA$ is also rather reminiscent of those in crystalline GaS polymorphs including a gap between 4.4 and $5.1 \AA$. However, more distant correlations are considerably broader or featureless reflecting the structural disorder in glassy gallium sulfide. Further details related to static and dynamic features in g-GaS were obtained using the first-principles simulations.

\subsection{First-principles molecular dynamics (FPMD)}

The standard $\mathrm{PBE}^{34}$ or PBEsol ${ }^{35}$ exchange-correlation functionals overestimate interatomic distances in chalcogenides and pnictides, ${ }^{78,79}$ also confirmed in our FPMD simulations. The use of hybrid functionals B3LYP78 or PBE080 improves the agreement with experiment. Figure 6(a) shows the experimental and FPMD/PBE0 interference functions $Q\left[S_{\mathrm{X}}(Q)-1\right]$ for glassy GaS, revealing a close similarity. The only notable difference is related to underestimated principle peak at $2.25 \AA^{-1}$ often associated with the small size of the FPMD simulation box, ${ }^{81} 16.58 \AA$ at 300 $\mathrm{K}$ in our case. As expected, the FPMD/PBEsol structure factor exhibits a systematic shift to lower scattering vectors, resulting in larger distances in $r$-space, Fig. S2 in ESI.
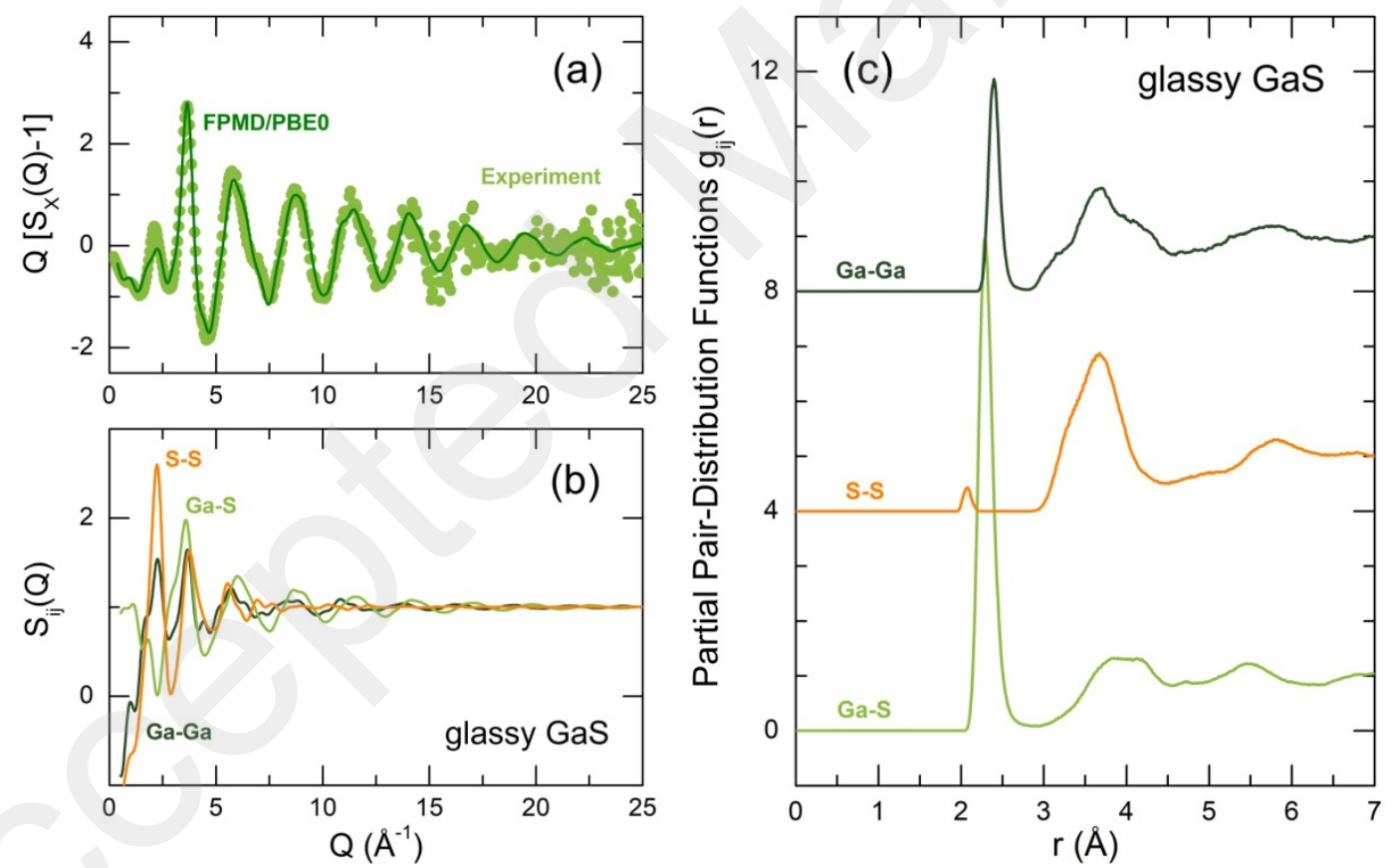

Fig. 6. Derived FPMD/PBE0 total and partial functions in $Q$ - and $r$-space for glassy GaS: (a) the experimental (circles) and FPMD (green line) X-ray interference function $Q\left[S_{\mathrm{X}}(Q)-1\right]$, (b) the partial structure factors $S_{\mathrm{ij}}(Q)$, and (c) the partial pair-distribution functions $g_{\mathrm{ij}}(r)$, where Ga-Ga (dark green), Ga-S (light green) and S-S (orange) atomic pairs are color-coded.

The partial structure factors $S_{\mathrm{ij}}(Q)$ are summarized in Fig. $6(\mathrm{~b})$ revealing the main contribution to the FSDP comes from Ga-Ga correlations. The $r$-space partials, Fig. 6(c), confirm mixed gallium local environment consisting of Ga-S $(\approx 2.30 \AA)$ and Ga-Ga $(\approx 2.40 \AA)$ nearest neighbors. The NN peaks are asymmetric having a higher- $r$ tail. The $g_{\mathrm{ij}}(r)$ exhibit also two unexpected features: (1) a small fraction of S-S homopolar bonds at $\approx 2.07 \AA$, also visible in Raman spectra of 
g-GaS, Fig. 2(a), and (2) a low-r shoulder $(\approx 3.1 \AA \AA)$ of the Ga-Ga second neighbor peak, related to short Ga-Ga correlations in edge-sharing structural units. These two features are absent in crystalline GaS polymorphs. ${ }^{13,14,77}$

The gallium and sulfur local coordination distributions are shown in Fig. 7. As expected, the average gallium environment is tetrahedral, $\left\langle N_{\mathrm{Ga}-\mathrm{X}}\right\rangle=3.93 \pm 0.03, \mathrm{X}=\mathrm{S}$ or Ga; and the four-fold coordinated Ga species are predominant, $93 \pm 2 \%$. Nevertheless, a small fraction of under- and over-coordinated gallium is present in g-GaS. The average mixed gallium coordination, $\left\langle N_{\mathrm{Ga}-\mathrm{X}}\right\rangle$ $=\left\langle N_{\mathrm{Ga}-\mathrm{S}}\right\rangle+\left\langle N_{\mathrm{Ga}-\mathrm{Ga}}\right\rangle \cong 3+1$, is consistent with that in crystalline GaS polymorphs. ${ }^{13,14,77}$ However, a wide NN distribution around central tetrahedral gallium is observed: one fifth of pure $\mathrm{GaS}_{4}$ tetrahedra, $62 \pm 2 \%$ of $\mathrm{Ga}\left(\mathrm{S}_{3} \mathrm{Ga}\right)$ mixed units $(100 \%$ in crystalline $\mathrm{GaS})$, and the remaining fraction of Ga-rich mixed entities including $1.1 \%$ of $\mathrm{Ga}\left(\mathrm{SGa}_{3}\right)$ polyhedra, see the inset in Fig. 7(b). Similar trends are observed for sulfur, Fig. 7(a). The average sulfur coordination is $\left\langle N_{S-X}\right\rangle=2.95 \pm 0.02$, and the trigonal $S$ species appear to be dominant, $80 \pm 2 \%$. The NN distribution around central trigonal sulfur is narrow, just $5 \pm 1 \%$ of mixed $S\left(\mathrm{Ga}_{2} \mathrm{~S}\right)$ units, the inset in Fig. 7(a). Resuming we note a very rigid network of glassy GaS with the average coordination number $\langle m\rangle=\left\langle N_{\mathrm{Ga}-\mathrm{X}}\right\rangle \times 1 / 2+\left\langle N_{\mathrm{S}-\mathrm{X}}\right\rangle \times 1 / 2=3.44 \pm 0.03$, comparable with that of amorphous silicon or germanium. The observed unusually rigid connectivity of g-GaS is atypical for chalcogenide glasses with a much lower average coordination, in most cases $2.2 \leq\langle m\rangle \leq 2.8$.
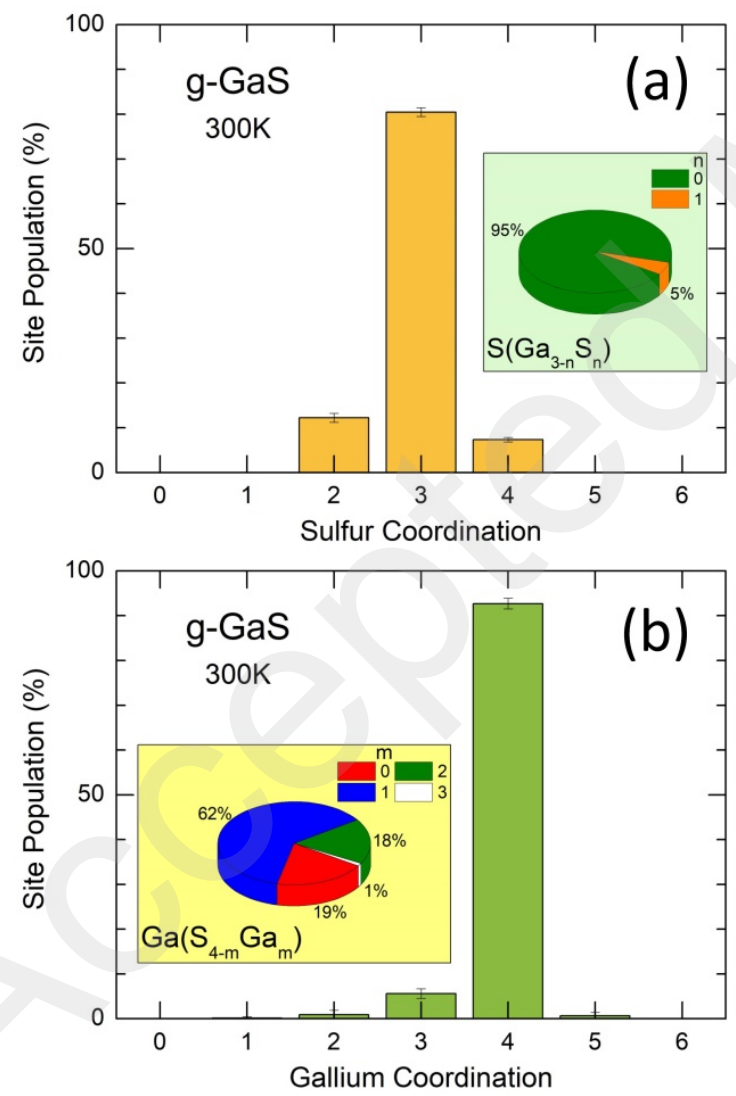

Fig. 7. Local coordination distributions for (a) sulfur and (b) gallium in glassy gallium sulfide. The insets show the nearest neighbor distributions for (a) trigonal central sulfur, and (b) tetrahedral central gallium.
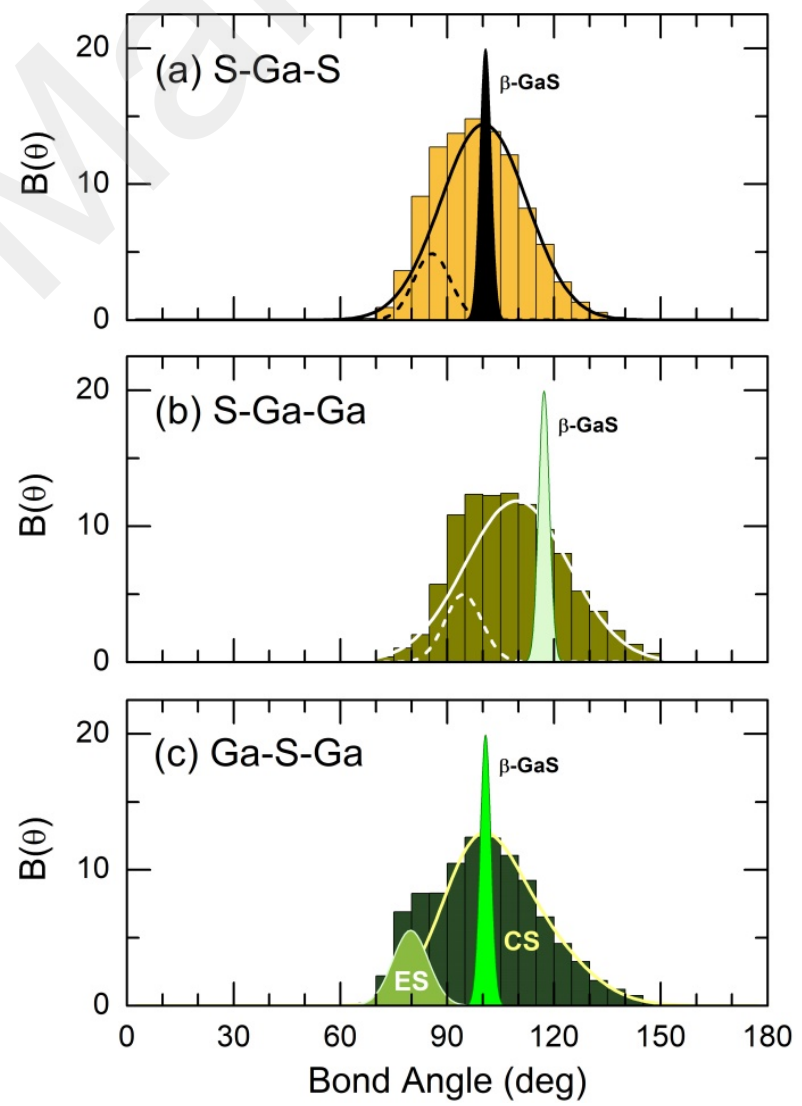

Fig. 8. Angular dependences $B(\theta)$ for (a) S-Ga-S, (b) $\mathrm{S}-\mathrm{Ga}-\mathrm{Ga}$, and (c) Ga-S-Ga triplets in glassy gallium sulfide in comparison with those in hexagonal GaS polymorph. ${ }^{13} \mathrm{~A}$ bimodal fitting of $B(\theta)$, related to edge- and corner-sharing polyhedra, is also shown. 
Angular dependences $B(\theta)$ of S-Ga-S, S-Ga-Ga, and Ga-S-Ga triplets are shown in Fig. 8 in comparison with hexagonal GaS. ${ }^{13}$ Broad $B(\theta)$ distributions appear to be a common feature for glassy gallium sulfide related to structural and topological disorder. The connectivity of Gacentered polyhedra is reflected by the Ga-S-Ga bond angles. The $B_{\mathrm{GaSGa}}(\theta)$ distribution is broad and asymmetric. The $B_{\mathrm{GaSGa}}(\theta)$ maximum at $100.7^{\circ}$ is consistent with that in hexagonal GaS. A low- $\theta$ shoulder at $\approx 80^{\circ}$ indicates a non-negligible fraction of edge-sharing (ES) Ga-S tetrahedra. Similar ES-contribution at $\theta(\mathrm{GeSGe})=82^{\circ}$ was observed in high-temperature $\mathrm{GeS}_{2}$ polymorph, consisting of edge- and corner-sharing $\mathrm{CS}^{-\mathrm{GeS}_{4}}$ tetrahedra, ${ }^{82}$ and Ge-S glasses. ${ }^{83,84}$ The fractional area of the $80^{\circ}$ feature, $14 \%$, is coherent with the ES/CS connectivity analysis of Ga-centered polyhedra and fitting results of the short (3.11 $\AA$, ES-units) and long (3.66 ̊, CS-polyhedra) GaGa second neighbor correlations, Fig. 6(c).

The geometry of Ga-S polyhedra, mostly Ga( $\left(\mathrm{S}_{4-m} \mathrm{Ga}_{m}\right)$ tetrahedra, is revealed by the S-Ga-S and SGa-Ga bond angles. The mixed $\mathrm{Ga}\left(\mathrm{S}_{3} \mathrm{Ga}\right)$ tetrahedra in hexagonal $\mathrm{GaS}$ have an axial distortion along the Ga-Ga bond and consequently different S-Ga-S $\left(100.76^{\circ}\right)$ and S-Ga-Ga $\left(117.2^{\circ}\right)$ bond angles, Fig. 8.13 The maximum of a broad and asymmetric $B_{\mathrm{SGaS}}(\theta)$ distribution in glassy gallium sulfide is similar to the crystal value, while that of $B_{\mathrm{SGaGa}}(\theta)$ is shifted to a tetrahedral angle, $109.6 \pm 0.4^{\circ}$. In other words, the average axial distortion of $\mathrm{Ga}\left(\mathrm{S}_{4-m} \mathrm{Ga}_{m}\right)$ tetrahedra appears to be reduced in g-GaS despite a strong structural disorder. A bimodal fitting of asymmetric angular distributions $B_{\mathrm{SGaS}}(\theta)$ and $B_{\mathrm{SGaGa}}(\theta)$ unveils a low $-\theta$ contribution of nearly identical fractional area, $13 \pm 1 \%$, Fig. $8(a, b)$. These low $\theta$ contributions are related to additional geometry distortions of the ES-polyhedra in glassy GaS.
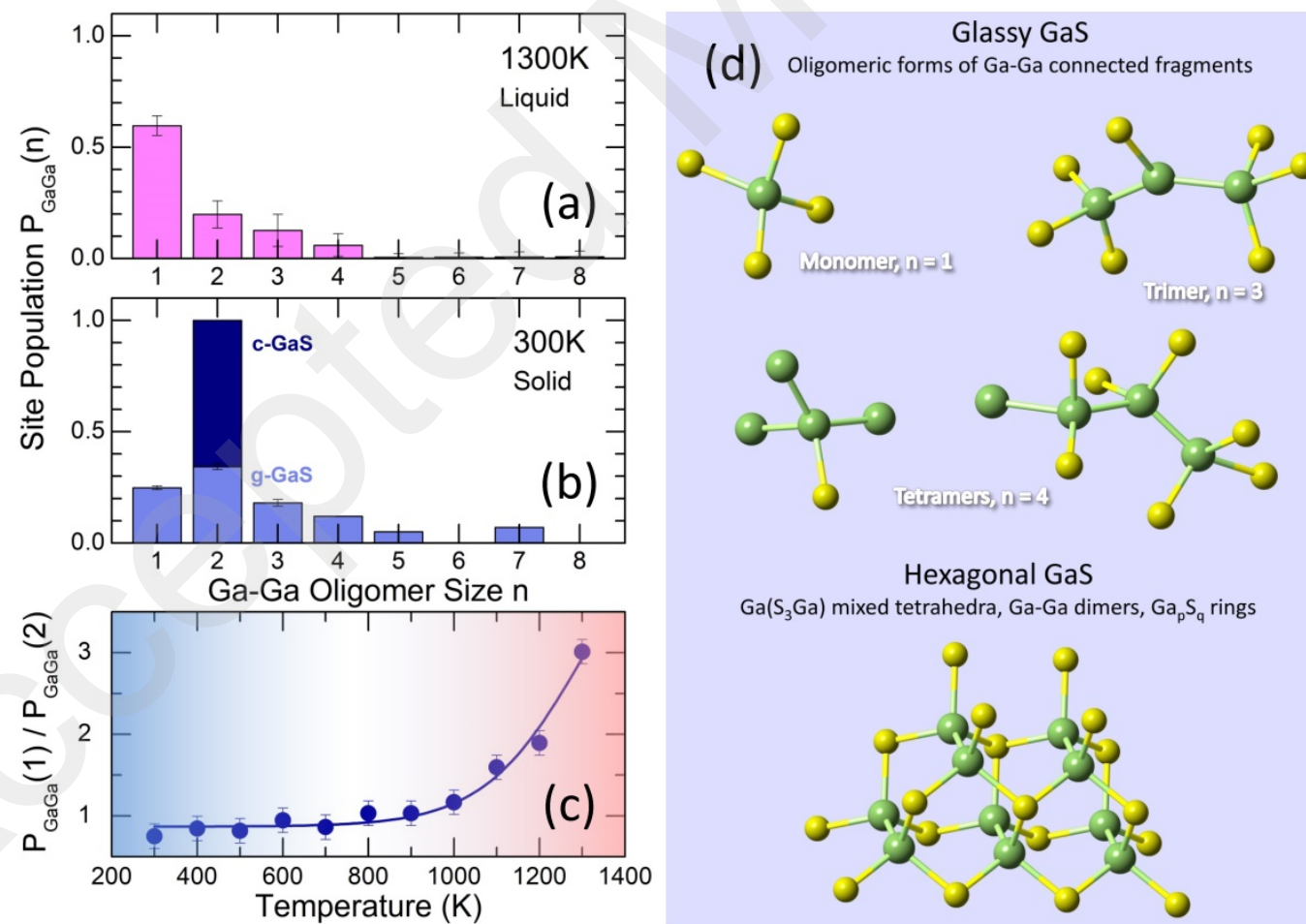

$\mathrm{Ga}\left(\mathrm{S}_{3} \mathrm{Ga}\right)$ mixed tetrahedra, $\mathrm{Ga}-\mathrm{Ga}$ dimers, $\mathrm{Ga}_{\mathrm{p}} \mathrm{S}_{\mathrm{q}}$ rings

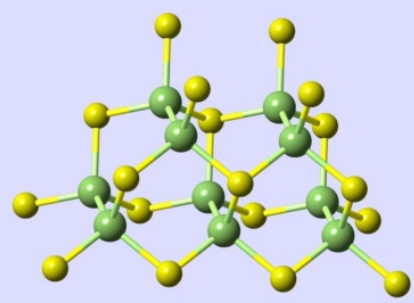

Fig. 9. Ga-Ga connected oligomer statistics in (a) liquid, and (b) glassy and crystalline GaS; (c) the Ga-Ga monomer-to-dimer ratio as a function of temperature, and (d) typical examples of Ga-Ga connected fragments in various forms of gallium sulfide.

The connectivity analysis reveals that $98 \%$ of Ga and S species in the FPMD simulation box are forming a single continuous network. A few homopolar S-S bonds in g-GaS are related to $\mathrm{S}_{2}$ 
dimers. In contrast, the Ga-Ga connected fragments show a wide size distribution, $P_{\mathrm{GaGa}}(n)$, dependent on temperature, Fig. 9(a,b), instead of only Ga-Ga dimers in crystalline GaS, Fig. $9(\mathrm{~b}, \mathrm{~d})$. In liquid $\mathrm{GaS}$ at $1300 \mathrm{~K}$, the maximum size $n$ of Ga-Ga connected long-living species is limited to tetramers, $\mathrm{Ga}_{4}$, but the majority of Ga fragments, $60 \pm 4 \%$, are monomers. In other words, the dimeric Ga-Ga connectivity of the crystal is broken in the melt. Cooling down the liquid, one observes the increasing $\mathrm{Ga}_{n}$ size up to $n=7$, corresponding to a few Ga-S polyhedra forming a chain, Fig. 9(d). Nevertheless, the dominant Ga-Ga connections in g-GaS are dimers, $34.2 \pm 1.2 \%$. Plotting the ratio $P_{\mathrm{GaGa}}(1) / P_{\mathrm{GaGa}}(2)$ as a function of temperature, one observes that dissociation of oligomers starts above $700 \mathrm{~K}$, Fig. $9(\mathrm{c})$, suggesting that the glass transition temperature $T_{\mathrm{g}}$ in $\mathrm{g}$-GaS presumably appears within $700 \mathrm{~K} \leq T_{\mathrm{g}} \leq 800 \mathrm{~K}$ range.

The intermediate range order in gallium sulfide is represented via $\mathrm{Ga}_{p} \mathrm{~S}_{q}$ ring statistics. The 2D layers in hexagonal $\mathrm{GaS}$ are exclusively built-up by 6-fold rings of two types: $\mathrm{Ga}_{4} \mathrm{~S}_{2}$ and $\mathrm{Ga}_{3} \mathrm{~S}_{3}$, Fig. $9(\mathrm{~d})$. The topological disorder in glassy and liquid $\mathrm{GaS}$ is well illustrated by the ring population $R_{c}(p+q),{ }^{48}$ where $3 \leq p+q \leq 11$, Fig. 10 . Basically, the small rings are present in a glass and normal liquid above the melting point, $T_{m}=1228 \pm 6 \mathrm{~K} .{ }^{85-87}$ The $R_{c}(p+q)$ maximum in glassy GaS is peaked at $p+q=6$ as in crystalline gallium sulfide. In liquid $\mathrm{GaS}$, a bimodal distribution is observed centered on both 4- and 6-fold rings. The ring size fluctuations are remarkably larger in a liquid, reflected by the ring population uncertainty, calculated over one picosecond of FPMD simulation time and shown as error bars in Fig. 10.

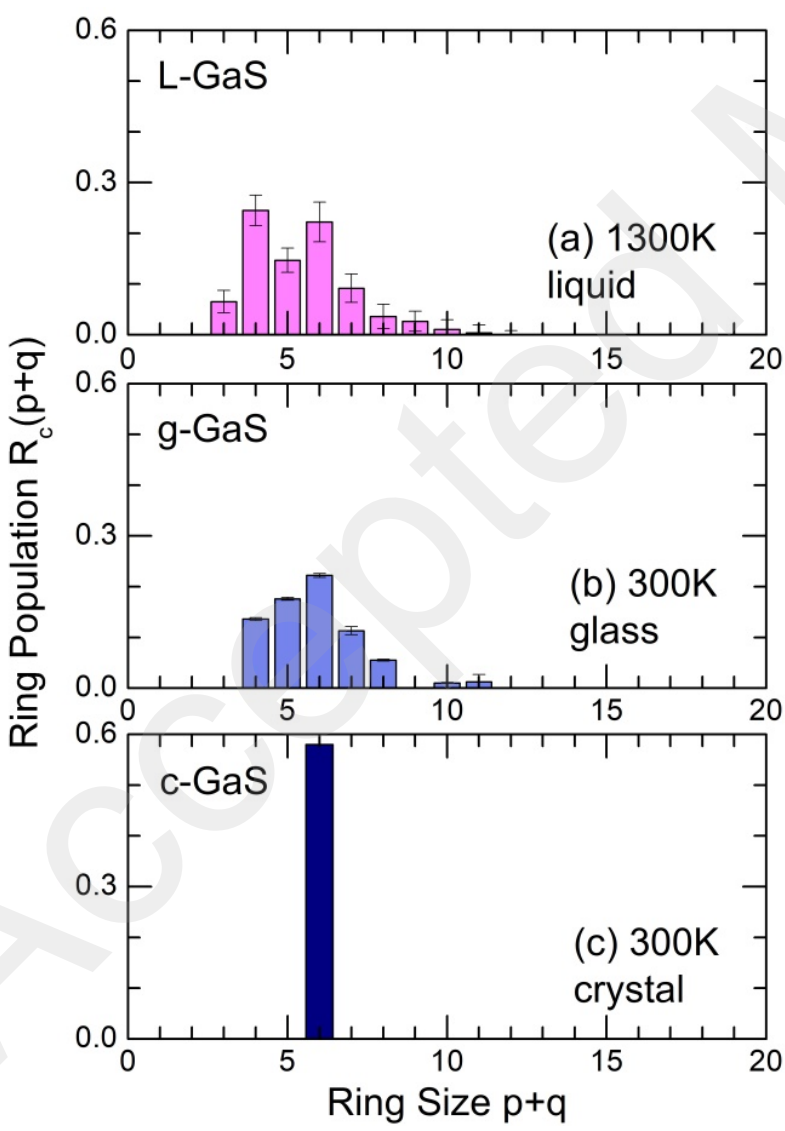

Fig. 10. Ring population $R_{c}(p+q)$ in (a) liquid, (b) glassy and (c) crystalline GaS calculated using the R.I.N.G.S. software. ${ }^{48}$

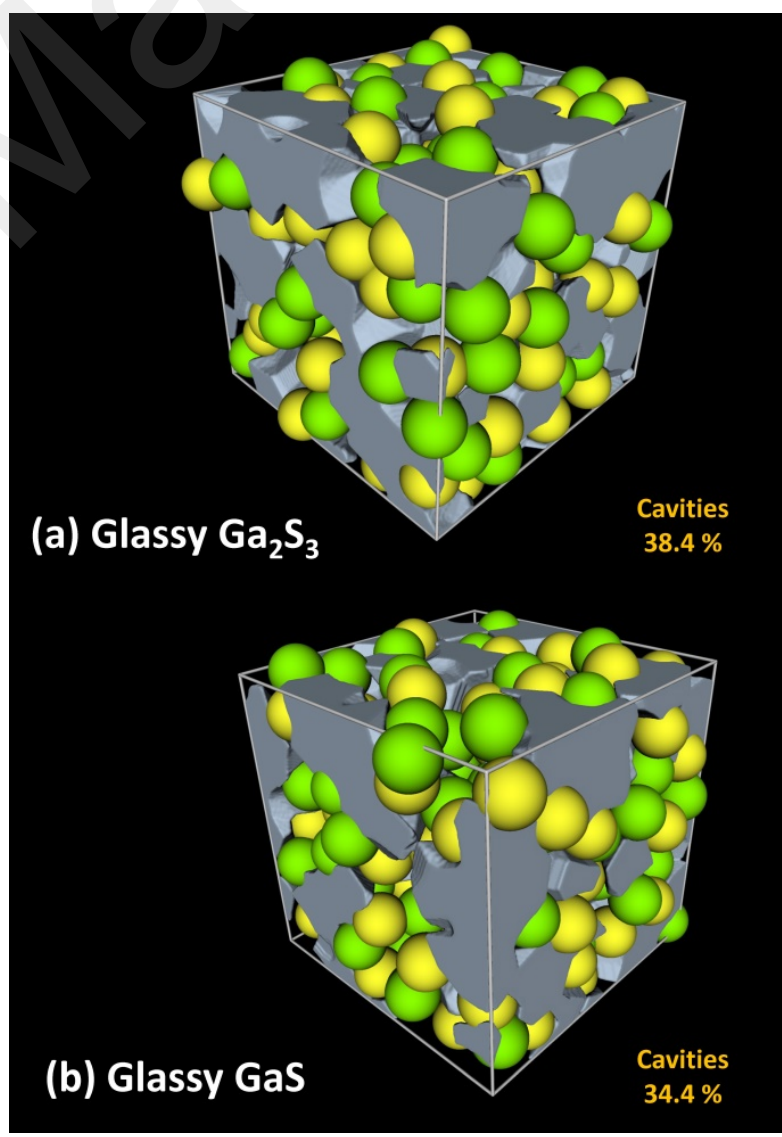

Fig. 11. Cavities in glassy (a) $\mathrm{Ga}_{2} \mathrm{~S}_{3}$ and (b) GaS calculated using the pyMolDyn program $^{50}$ and Dirichlet-Voronoi tessellation. 
Glassy GaS has a higher packing density compared to usual gallium sulfide glasses reflected by the macroscopic number density, 0.04390 atoms $\AA^{-1}$ (g-GaS) vs. 0.037-0.041 atoms $\AA^{-1}\left(\mathrm{Ga}_{2} \mathrm{~S}_{3}\right.$ $\mathrm{GeS}_{2}$ glasses) or molar volume. At a microscopic level, the volume of cavities in glassy GaS, calculated using the Dirichlet-Voronoi tessellation ${ }^{50}$, Fig. 11, is also lower compared to that in glassy $\mathrm{Ga}_{2} \mathrm{~S}_{3}$ (a preliminary FPMD modeling), $34.4 \%$ vs. $38.4 \%$, respectively. Consequently, a small FSDP in g-GaS compared to gallium sulfide glasses and semi-crystalline $\mathrm{MM}-\mathrm{Ga}_{2} \mathrm{~S}_{3}$, Fig. 4, is related to frustration in the disordered network, associated with small available free space ${ }^{88}$ and decreasing spatial repeatability of Ga-centered tetrahedra at intermediate range scale. Similar trend was found earlier in $\mathrm{GeS}_{-} \mathrm{GeS}_{2}$ glasses. ${ }^{73}$

Figure 12 shows typical Ga and S mean-square displacements (MSD), $\left\langle r^{2}(t)\right\rangle$, as a function of the FPMD simulation time $t$ and temperature

$$
\left\langle r^{2}(t)\right\rangle=\left\langle\frac{1}{N_{i}}\left\{\sum_{i=1}^{N_{i}}\left[r_{i}(t)-r_{i}(0)\right]^{2}\right\}\right\rangle,
$$

where $r_{i}(0)$ and $r_{i}(t)$ are the positions of particle $i$ for the initial time and time $t$, respectively, $N_{i}$ the total number of particles in the simulation box, and the angle brackets represent the average over initial times.
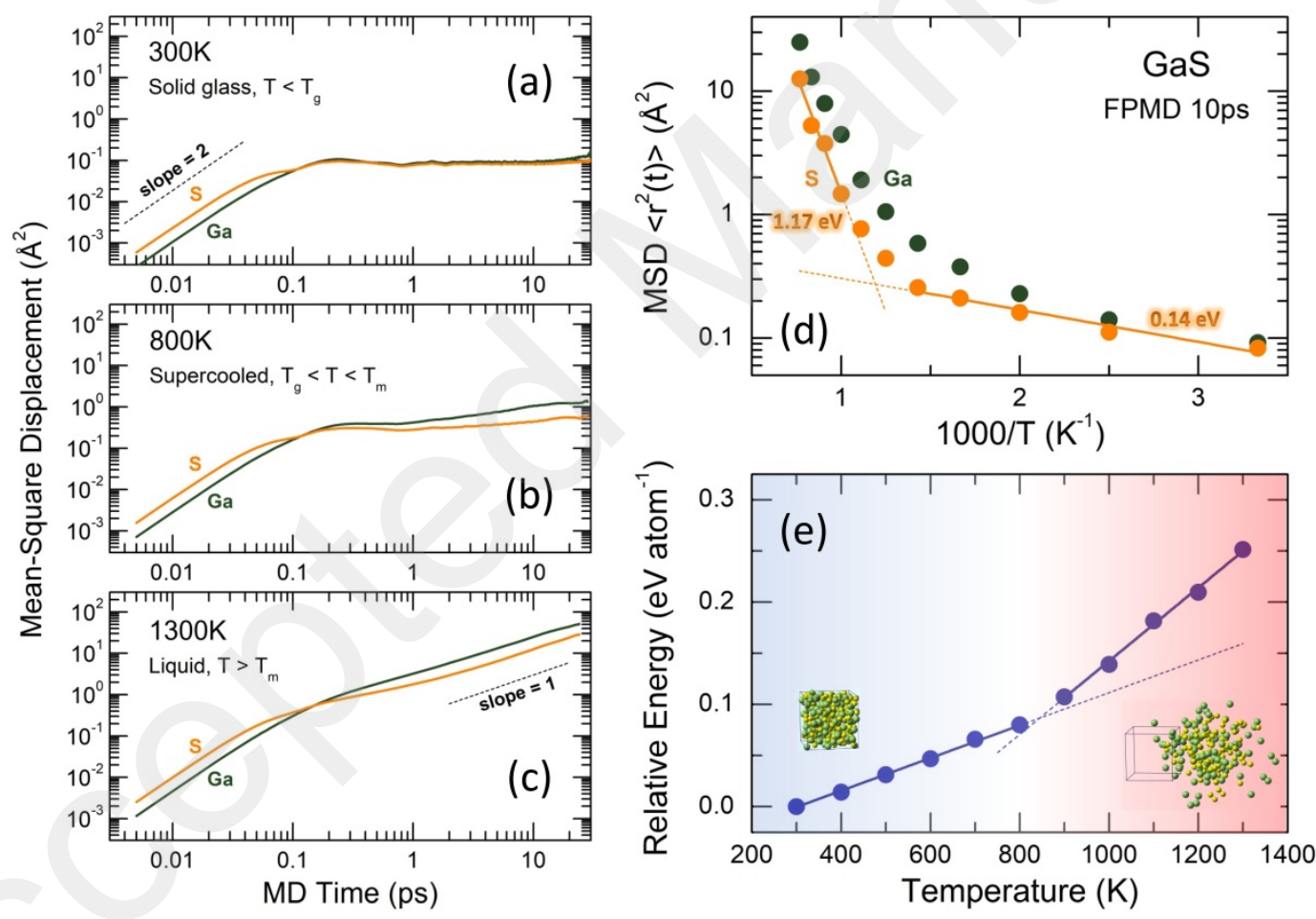

Fig. 12. Mean-square displacements in (a) glassy, (b) supercooled, and (c) normal GaS liquid at $300 \mathrm{~K}$, $800 \mathrm{~K}$ and $1300 \mathrm{~K}$, respectively, plotted as a function of FPMD simulation time; (d) Ga and S mean-square displacements at $10 \mathrm{ps}$ in Arrhenius coordinates; (d) the average relative energy per atom as a function of temperature; the insets show the snapshots of the FPMD simulation boxes at $300 \mathrm{~K}$ and $1300 \mathrm{~K}$, respectively. See text for further details.

Three characteristic regimes are seen in Fig. 12(a-c). The ballistic regime is observed at $t \lesssim 30$ fs and characterized by a slope $s=2$ on a $\log$-log scale 89

$\left\langle r^{2}(t)\right\rangle \propto\left(k_{\mathrm{B}} T / m\right) t^{2}$, 
where $k_{\mathrm{B}}$ and $T$ are the Boltzmann constant and temperature, and $m$ is the particle mass. The diffusive behavior appears at high $T$ and $t$ and exhibits a slope $s=1$, Fig. 12(c)

$\left\langle r^{2}(t)\right\rangle \propto D_{i} t$

where $D_{i}$ is the average diffusion coefficient of particles $i$. Finally, a plateau is observed between the two regimes at intermediate time scales and temperatures related to atomic vibrations and localized motion. ${ }^{90}$ The MSD is either constant or $\left\langle r^{2}(t)\right\rangle \propto t^{s}$, where $0 \leq s<1$.

Except the ballistic regime, the mobility of gallium species is higher than that of sulfur. In addition, the sulfur MSD exhibit a plateau, $\left\langle r^{2}(t)\right\rangle \approx$ const, over a wide time window, $0.3 \lesssim t \lesssim 30$ ps, below $T \leq 700 \mathrm{~K}$, see Fig. S3 in ESI. Above $800 \mathrm{~K}$, the localized motion becomes predominant for both $\mathrm{Ga}$ and $\mathrm{S}$, and in the vicinity of the melting point, $T_{m} \approx 1230 \mathrm{~K}$, the atomic mobility follows the Einstein relation (7). Different temperature domains are visible more clearly using the Arrhenius plot, $\log \left\langle r^{2}(t=10 \mathrm{ps})\right\rangle$ vs. $T^{-1}$, Fig. 12(d). The localized motion/vibrations at $T \leq$ $700 \mathrm{~K}$ are characterized by small apparent activation energy, $\approx 0.14 \mathrm{eV}$, and negligible sulfur MSD range, $0.08 \leq\left\langle r^{2}(t)\right\rangle \leq 0.3 \AA^{2}$. The long-range diffusion/viscous flow, $T \gtrsim 1000 \mathrm{~K}$, shows a much higher activation barrier, $\approx 1.2 \mathrm{eV}$, comparable with that found in macroscopic viscosity measurements.91,92 The observed difference is well illustrated by two snapshots of the FPMD simulation boxes taken at $300 \mathrm{~K}$ and $1300 \mathrm{~K}$, the insets in Fig. $12(\mathrm{e})$. The results are consistent with previous assumption, Fig. 9 and the related text, that the presumable glass transition in gGaS occurs between $700 \mathrm{~K}<T_{\mathrm{g}}<800 \mathrm{~K}$. We also note that this estimation of $T_{\mathrm{g}}$ scales with the melting point of gallium sulfide, $1223 \mathrm{~K} \leq T_{m} \leq 1235 \mathrm{~K}$, and a well-known principle, $T_{\mathrm{g}} \approx 2 / 3 T_{m}$. Finally, the average relative energy per atom, $\left\langle E_{i}\right\rangle$, in the FPMD simulation box exhibits a drastic increase of the $\partial\left\langle E_{i}\right\rangle / \partial T$ derivative by a factor of 2 above $800 \mathrm{~K}$, presumably related to the onset of viscous flow and changing the accessible energy landscape above $T_{\mathrm{g}} \cdot{ }^{93}$

Resuming, the diffraction results supported by FPMD simulations are consistent with exceptionally high laser-induced damage threshold of glassy GaS suggesting the superior NLO properties and a possible NLO crossover during a glass-crystal phase transition.

\section{Conclusions}

Pulsed laser deposition yields transparent, uniform and vitreous gallium sulfide layers of nearly stoichiometric $\mathrm{GaS}$ composition starting from a $\mathrm{Ga}_{2} \mathrm{~S}_{3}$ target. The difference in chemical composition is certainly related to a disproportionation of $\mathrm{Ga}_{2} \mathrm{~S}_{3}$ molecular fragments in the plasma plume. The gallium monosulfide PLD layers are characterized by a good transparency from visible to mid-IR spectral region, $0.53 \leq \lambda \leq 12 \mu \mathrm{m}$, with the band gap of $2.34 \mathrm{eV}$ and high refractive index $n_{\mathrm{R}}=2.50 \pm 0.01$ at $0.8 \leq \lambda \leq 2.5 \mu \mathrm{m}$. The excellent high-power UV and laserinduced damage threshold, $1.4 \mathrm{TW} \mathrm{cm}^{-2}$ at $780 \mathrm{~nm}$, superior to a vast majority of the studied chalcogenide glasses, suggests a large nonlinear optical susceptibility of the third order $\chi^{3}$.

The structural basis of exceptional NLO properties, studied by Raman spectroscopy, high-energy X-ray diffraction and supported by first-principles molecular dynamics, resides in rigid tetrahedral structure of the obtained layers with the average coordination number $\langle m\rangle=$ $3.44 \pm 0.03$, drastically different from typical chalcogenide glasses having $2.2 \leq\langle m\rangle \leq 2.8$. 
Tetrahedral Ga and three-fold coordinated S species are forming a continuous network, whose molecular architecture is characterized by a strong chemical and topological disorder compared to crystalline GaS polymorphs. In addition, this rigid network has a relatively small fraction of microscopic voids and cavities (34.4\%) reducing the atomic mobility. The FPMD simulations also reveal a glass transition in the GaS PLD layers between $700<T_{\mathrm{g}}<800 \mathrm{~K}$ detectable through Ga-Ga oligomer dissociation, local and long-range diffusional motion and a change in the average energy per atom. The estimated $T_{\mathrm{g}}$ is consistent with a well-known relation, $T_{\mathrm{g}} \approx 2 / 3 T_{m}$, where the melting point of GaS is $T_{m}=1228 \mathrm{~K}$.

A glass-crystal phase transition in gallium monosulfide is expected to be accompanied by a drastic change in the NLO properties from a large $\chi^{3}$ in isotropic glass to a strong SHG in a noncentrosymmetric crystal, opening up a new dimension in the PCM photonics and memory applications from visible to mid-IR.

\section{Acknowledgments}

This work was supported by the Ministry of Science and Higher Education under agreement 075-15-2019-1950; state assignment FSRC 'Crystallography and Photonics' Russian Academy of Sciences. The experiments at the SPring-8 were approved by the Japan Synchrotron Radiation Research Institute (proposal No. 2017A1067) and supported by the Centre for Advanced Science and Technology (Japan). The work at Tallinn University of Technology (Estonia) was supported by the European Union through the European Regional Development Fund project 'Center of Excellence' TK141. The optical measurements in part were carried out in the resource center of St. Petersburg State University: 'Center for Optical and Laser Materials Research'. The FPMD simulations were carried out using the HPC computing resources at Lomonosov Moscow State University and at the ILIT RAS in Shatura (Moscow Region). This work was also granted access to the HPC resources of IDRIS (France) under the allocation 2019-A0070910639 made by GENCI (Grand Equipement National de Calcul Intensif) and using the CALCULCO computing platform, supported by SCoSI/ULCO (Service COmmun du Système d'Information de l'Université du Littoral Côte d'Opale). E. B. is also grateful to Dr. F. Sava (National Institute of Materials Physics, Romania) for providing a gallium sulfide film used in preliminary measurements.

\section{Supplementary information}

High-energy X-ray diffraction measurements at SPring-8 (Hyogo Prefecture, Japan); experimental and simulated FPMD/PBEsol X-ray pair-distribution functions $g_{\mathrm{X}}(r)$ of glassy GaS; mean-square displacements $\left\langle r^{2}(t)\right\rangle$ of Ga and S species as a function of FPMD time $t$ and temperature $T$. 


\section{References}

1 S. Ovshinsky, Reversible electrical switching phenomena in disordered structures, Phys. Rev. Lett., 1968, 21, 1450-1453.

2 N. Yamada, E. Ohno, K. Nishiuchi, N. Akahira, and M. Takao, Rapid-phase transitions of GeTe$\mathrm{Sb}_{2} \mathrm{Te}_{3}$ pseudobinary amorphous thin films for an optical disk memory, J. Appl. Phys., 1991, 69, 2849-2856.

3 M. Wuttig and N. Yamada, Phase-change materials for rewriteable data storage, Nature Mater., 2007, 6, 824-832.

4 C. Ríos, M. Stegmaier, P. Hosseini, D. Wang, T. Scherer, C. D. Wright, H. Bhaskaran and W. H. P. Pernice, Integrated all-photonic non-volatile multi-level memory, Nature Photon., 2015, 9, 725732.

5 W. Zhang, R. Mazzarello, M. Wuttig and E. Ma, Designing crystallization in phase-change materials for universal memory and neuro-inspired computing, Nature Rev. Mater., 2019, 4, 150-168.

6 W. Dong, H. Liu, J. K. Behera, L. Lu, R. J. H. Ng, K. V. Sreekanth, X. Zhou, J. K. W. Yang, and R. E. Simpson, Wide bandgap phase change material tuned visible photonics, Adv. Funct. Mater., 2018, 29, 1806181.

7 J. Faneca, L. Trimby, I. Zeimpekis, M. Delaney, D. W. Hewak, F. Y. Gardes, C. D. Wright, and A. Baldycheva, On-chip sub-wavelength Bragg grating design based on novel low loss phase-change materials, Opt. Exp., 2020, 28, 12019-12031.

8 S. Barnier, M. Guittard and J. Flahaut, Etude de verres de chalcogénures contenant de l'europium divalent système EuS-Ga $\mathrm{S}_{3}-\mathrm{GeS}_{2}$, Mater. Res. Bull., 1980, 15, 689-705.

9 Yu. S. Tver'yanovich and A. Tverjanovich, Rare-earth doped chalcogenide glasses, in Semiconducting Chalcogenide Glass, ed. R. Fairman and B. Ushkov, Elsevier, Amsterdam, 2004, pp. 169-207.

10 A. B. Seddon, Z. Tang, D. Furniss, S. Sujecki and T. M. Benson, Progress in rare earth-doped midinfrared fiber lasers, Opt. Exp., 2010, 18, 26704-26719.

11 J. Heo and W. J. Chung, Rare-earth-doped chalcogenide glass for lasers and amplifiers, in Chalcogenide Glasses: Preparation, Properties and Applications, ed. J.-L. Adam and X. Zhang, Woodhead Publ., Oxford, 2014, pp. 347-380.

12 M.-J. Zhang, X.-M. Jiang, L.-J. Zhou and G.-C. Guo, Two phases of $\mathrm{Ga}_{2} \mathrm{~S}_{3}$ : promising infrared secondorder nonlinear optical materials with very high laser induced damage thresholds, J. Mater. Chem. C, 2013, 1, 4754-4760; D. M. Ezhov, A. S. Tanichev, A. B. Kuznetsov, K. A. Kokh, G. V. Lanskii, Y. M. Andreev, and V. A. Svetlichnyi, SHG in $\gamma-\mathrm{Ga}_{2} \mathrm{~S}_{3}$ powder. Proc. SPIE, 2018, 10614, International Conference on Atomic and Molecular Pulsed Lasers XIII, 1061424.

13 A. Kuhn, A. Bourdon, J. Rigoult and A. Rimsky, Charge-density analysis of GaS, Phys. Rev. B: Condens. Matter Mater. Phys., 1982, 25, 4081-4088.

14 M. P. Pardo and J. Flahaut, Sur une nouvelle forme de GaS, rhomboédrique 3R métastable: Formation et étude structurale, Mater. Res. Bull., 1987, 22, 323-329.

15 K. Allakhverdiev, F. Ismailov, L. Kador and M. Braun, Second-harmonic generation in GaS crystals, Solid State Commun., 1997, 104, 1-3. X. F. Wang, Z. W. Wang, J. G. Yu, C. L. Liu, X. J. Zhao, and Q. H. Gong, Large and ultrafast third-order optical nonlinearity of $\mathrm{GeS}_{2}-\mathrm{Ga}_{2} \mathrm{~S}_{3}-\mathrm{CdS}$ chalcogenide glass, Chem. Phys. Lett., 2004, 399, 230-233.

optical properties of $\mathrm{GeS}_{2}-\mathrm{Ga}_{2} \mathrm{~S}_{3}-\mathrm{AgCl}$ chalcohalide glasses. Opt. Express, 2007, 15, 2398-2408.

18 G. Micocci, R. Rella and A. Tepore, Conductivity and optical absorption in amorphous gallium sulphide thin films, Thin Solid Films, 1989, 172, 179-183.

19 S. Suh and D. M. Hoffman, Chemical vapor deposition of gallium sulfide thin films, Chem. Mater. 2000, 12, 2794-2797.

20 M. L. Mejía, G. Reeske and B. J. Holliday, Gallium-containing conducting metallopolymers which display chemically tunable reactivity for the growth of $\mathrm{Ga}_{2} \mathrm{~S}_{3}$ semiconducting nanoparticles, Chem. Commun., 2010, 46, 5355-5357.

21 K. Kato and N. Umemura, Sellmeier equations for GaS and GaSe and their applications to the nonlinear optics in $\mathrm{GaS}_{x} \mathrm{Se}_{1-x}$, Opt. Lett., 2011, 36, 746-747.

22 Z. Huang, J.-G. Huang, K. A. Kokh, V. A. Svetlichnyi, A. V. Shabalina, Yu. M. Andreev, and G. V. Lanskii, $\mathrm{Ga}_{2} \mathrm{~S}_{3}$ : Optical properties and perspectives for $\mathrm{THz}$ applications, in 40th Intern. Conf. Infrared, Millimeter, and Terahertz Waves, Hong Kong, Aug. 23-28, 2015, DOI: 10.1109/IRMMWTHz.2015.7327440. 
M. Popescu, F. Sava, A. Lörinczi, A. Velea, I. D. Simandan, A. C. Galca, E. Matei, G. Socol, F. Gherendi, D. Savastru, and S. Miclos, Amorphous thin films in the gallium-chalcogen system, Phys. Stat. Solidi $B, 2016,253,1033-1037$.

X. Wang, Y. Sheng, R.-J. Chang, J. K. Lee, Y. Zhou, S. Li, T. Chen, H. Huang, B. F. Porter, H. Bhaskaran, and J. H. Warner, Chemical vapor deposition growth of two-dimensional monolayer gallium sulfide crystals using hydrogen reduction of $\mathrm{Ga}_{2} \mathrm{~S}_{3}$, ACS Omega, 2018, 3, 7897-7903. J. Kim, W. Park, J.-H. Lee and M.-J. Seong, Simultaneous growth of $\mathrm{Ga}_{2} \mathrm{~S}_{3}$ and GaS thin films using physical vapor deposition with GaS powder as a single precursor, Nanotechnology, 2019, 30, 384001.

J. L. Brebner and G. Fischer, The optical absorption range of GaS, Can. J. Phys., 1963, 41, 561-563.

A. Tomas, M. P. Pardo, M. Guittard, M. Guymont and R. Famery, Détermination des structures des formes $\alpha$ et $\beta$ de $\mathrm{Ga}_{2} \mathrm{~S}_{3}$, Mater. Res. Bull., 1987, 22, 1549-1554.

C. Y. Jones, J. C. Bryan, K. Kirschbaum and J. G. Edwards, Refinement of the crystal structure of digallium trisulfide, $\mathrm{Ga}_{2} \mathrm{~S}_{3}$, Z. Kristallogr. NCS, 2001, 216, 327-328.

F. Hindle, M. Miloshova, E. Bychkov, C. J. Benmore and A. C. Hannon, Structural analysis of $x \mathrm{CsCl}(1-x) \mathrm{Ga}_{2} \mathrm{~S}_{3}$ glasses, J. Non-Cryst. Solids, 2008, 354, 134-137.

30 I. Pethes, V. Nazabal, R. Chahal, B. Bureau, I. Kaban, S. Belin, and P. Jóvári, Local motifs in $\mathrm{GeS}_{2}-$ $\mathrm{Ga}_{2} \mathrm{~S}_{3}$ glasses, J. Alloys Compounds, 2016, 673, 149-157.

K. Ohara, Y. Onodera, S. Kohara, C. Koyama, A. Masuno, A. Mizuno, J. T. Okada, S. Tahara, Y. Watanabe, H. Oda, Y. Nakata, H. Tamaru, T. Ishikawa, and O. Sakata, Accurate synchrotron hard Xray diffraction measurements on high-temperature liquid oxides, Intern. J. Microgravity Sci. Appl., $2020,37,370202$.

S. Kohara, M. Itou, K. Suzuya, Y. Inamura, Y. Sakurai, Y. Ohishi, and M. Takata, Structural studies of disordered materials using high-energy X-ray diffraction from ambient to extreme conditions, $J$. Phys.: Condens. Matter, 2007, 19, 506101.

33 J. Hutter, M. Iannuzzi, F. Schimann and J. VandeVondele, CP2K: Atomistic simulations of condensed matter systems, Wiley Interdisciplinary Reviews: Computational Molecular Science, 2014, 4, 15-25.

34 J. P. Perdew, K. Burke and M. Ernzerhof, Generalized gradient approximation made simple, Phys. Rev. Lett., 1996, 77, 3865-3868.

35 J. P. Perdew, A. Ruzsinszky, G. I. Csonka, O. A. Vydrov, G. E. Scuseria, L. A. Constantin, X. Zhou and K. Burke, Restoring the density-gradient expansion for exchange in solids and surfaces, Phys. Rev. Lett., 2008, 100, 136406.

J. P. Perdew, M. Ernzerhof and K. Burke, Rationale for mixing exact exchange with density functional approximations, J. Chem. Phys., 1996, 105, 9982-9985.

37 C. Adamo and V. Barone, Toward reliable density functional methods without adjustable parameters: the PBE0 model, J. Chem. Phys., 1999, 110, 6158-6170.

38 J. Akola, R. O. Jones, S. Kohara, S. Kimura, K. Kobayashi, M. Takata, T. Matsunaga, R. Kojima, and N. Yamada, Experimentally constrained density-functional calculations of the amorphous structure of the prototypical phase-change material $\mathrm{Ge}_{2} \mathrm{Sb}_{2} \mathrm{Te}_{5}$, Phys. Rev. B: Condens. Matter Mater. Phys., 2009, 80, 020201.

39 T. Matsunaga, J. Akola, S. Kohara, T. Honma, K. Kobayashi, E. Ikenaga, R. O. Jones, N. Yamada, M. Takata, and R. Kojima, From local structure to nanosecond recrystallization dynamics in AgInSbTe phase-change materials, Nature Mater., 2011, 10, 129-134.

40 O. Gereben, P. Jovari, L. Temleitner and L. Pusztai, A new version of the RMC++ Reverse Monte Carlo programme, aimed at investigating the structure of covalent glasses, J. Optoelectron. Adv. Mater., 2007, 9, 3021-3027.

41 O. Gereben and L. Pusztai, RMC_POT, a computer code for Reverse Monte Carlo modeling the structure of disordered systems containing molecules of arbitrary complexity, J. Comp. Chem., 2012, 33, 2285-2291.

42 J. VandeVondele and J. Hutter, Gaussian basis sets for accurate calculations on molecular systems in gas and condensed phases, J. Chem. Phys., 2007, 127, 114105.

43 F. Weigend and R. Ahlrichs, Balanced basis sets of split valence, triple zeta valence and quadruple zeta valence quality for $\mathrm{H}$ to Rn: Design and assessment of accuracy, Phys. Chem. Chem. Phys., $2005,7,3297-3305$.

44 S. Goedecker, M. Teter and J. Hutter, Separable dual-space Gaussian pseudopotentials, Phys. Rev. B: Condens. Matter Mater. Phys., 1996, 54, 1703-1710.

45 C. Hartwigsen, S. Goedecker and J. Hutter, Relativistic separable dual-space Gaussian pseudopotentials from H to Rn, Phys. Rev. B: Condens. Matter Mater. Phys., 1998, 58, 3641-3662. 
S. Nosé, A molecular dynamics method for simulations in the canonical ensemble, Mol. Phys., 1984, 52, 255-268.

47 W. G. Hoover, Canonical dynamics: equilibrium phase-space distributions, Phys. Rev. A: Atom., Mol., Opt. Phys., 1985, 31, 1695-1697.

S. Le Roux and P. Jund, Ring statistics analysis of topological networks: New approach and application to amorphous $\mathrm{GeS}_{2}$ and $\mathrm{SiO}_{2}$ systems, Comput. Mater. Sci., 2010, 49, 70-83.

49 S. Kohara, H. Ohno, M. Tabaka, T. Usuki, H. Morita, K. Suzuya, J. Akola, and L. Pusztai, Lead silicate glasses: Binary network-former glasses with large amounts of free volume, Phys. Rev. B: Condens. Matter Mater. Phys., 2010, 82, 134209.

I. Heimbach, F. Rhiem, F. Beule, D. Knodt, J. Heinen, and R. O. Jones, pyMolDyn: Identification, structure, and properties of cavities/vacancies in condensed matter and molecules, J. Comput. Chem., 2017, 38, 389-394.

51 M. J. Taylor, Raman and infrared spectra and vibrational assignments of gallium (II) sulphide, J. Raman Spectrosc., 1973, 1, 355-58.

J. P. van der Ziel, A. E. Meixner and H. M. Kasper, Raman scattering from $\beta$-GaS, Solid State Commun., 1973, 12, 1213-1215.

G. Lucazeau and J. Leroy, Etude vibrationnelle de $\alpha \mathrm{Ga}_{2} \mathrm{~S}_{3}$, Spectrochim. Acta A, 1978, 34, 29-32.

B. Eckert and R. Steudel, Molecular spectra of sulfur molecules and solid sulfur allotropes, in Elemental Sulfur und Sulfur-Rich Compounds II, Topics in Current Chemistry, vol. 231, ed. R. Steudel, Springer, Berlin, 2003, pp. 31-98.

A. R. Barron and A. N. MacInnes, Gallium: inorganic chemistry, in Encyclopedia of Inorganic Chemistry, ed. R. B. King, John Wiley and Sons, Hoboken, NJ, 1994, pp. 100-110.

56 J. A. Roberts and A. W. Searcy,

57 J. J. BelBruno, E. Sanville, A. Burnin, A. K. Muhangi and A. Malyutin, Structural calculations and experimental detection of small $\mathrm{Ga}_{m} \mathrm{~S}_{n}$ clusters using time-of-flight mass spectrometry, Chem. Phys. Lett., 2009, 478, 132-138.

58 S. Bereznev, H. Kocharyan, N. Maticiuc, R. Naidu, O. Volobujeva, A. Tverjanovich, and J. Kois, Onestage pulsed laser deposition of conductive zinc oxysulfide layers, Appl. Surf. Sci., 2017, 425, 722727.

59 R. Swanepoel, Determination of the thickness and optical constants of amorphous silicon, J. Phys. E: Sci. Instrum., 1983, 16, 1214-1222.

60 A. R. Hilton, Chalcogenide Glasses for Infrared Optics, Mc Graw Hill, New York, 2010, 279 pp.

61 Y. Yang, Z. Yang, P. Lucas, Y. Wang, Z. Yang, A. Yang, B. Zhang, and H. Tao, Composition dependence of physical and optical properties in Ge-As-S chalcogenide glasses, J. Non-Cryst. Solids, 2016, 440, 38-42.

62 N. F. Mott and E. A. Davis, Electronic Processes in Non-Crystalline Materials, $2^{\text {nd }}$ edition, Clarendon Press, Oxford, 1979, pp. 272-300.

63 C.-H. Ho and H.-H. Chen, Optically decomposed near-band-edge structure and excitonic transitions in $\mathrm{Ga}_{2} \mathrm{~S}_{3}$, Sci. Rep., 2014, 4, 6143.

64 K. A. Kokh, Z.-M. Huang, J.-G. Huang, Y.-Q. Gao, B. Uralbekov, J. Panomarev, I. N. Lapin, V. A. Svetlichnyi, G. V. Lanskii, and Yu. M. Andreev, Study of $\mathrm{Ga}_{2} \mathrm{~S}_{3}$ crystals grown from melt and $\mathrm{PbCl}_{2}$ flux, Mater. Res. Bull., 2016, 84, 462-467.

65 I. Caraman, S. Evtodiev, D. Untila, L. Palachi, O. Susu, I. Evtodiev, and V. Kantser, Optical and photoelectric properties of planar structures obtained by thermal annealing of $\mathrm{Ga}_{2} \mathrm{~S}_{3}$ plates in $\mathrm{Zn}$ vapors, Phys. Status Solidi A, 2017, 214, 1700808.

M. Frumar, B. Frumarová, T. Wágner and P. Nĕmec, Photo-induced phenomena in amorphous and glassy chalcogenides, in Photo-Induced Metastability in Amorphous Semiconductors, ed. A. Kolobov, Wiley-VCH, Weinheim, 2003, pp. 23-44.

67 O. Caulier, D. Le Coq, L. Calvez, E. Bychkov, and P. Masselin, Free carrier accumulation during direct laser writing in chalcogenide glass by light filamentation, Opt. Express, 2011, 19, 2008820096.

68 K. Tanaka, Nonlinear optical properties of photonic glasses, in Optical Properties of Condensed Matter and Applications, ed. J. Singh, John Wiley and Sons, Chichester, 2006, pp. 215-233.

69 A. Zakery and S.R. Elliott, Optical Nonlinearities in Chalcogenide Glasses and their Applications, Springer, Berlin, 2007, 199 pp.

70 M. Frumar, J. Jedelsky, B. Frumarova, T. Wagner and M. Hrdlicka, Optically and thermally induced changes of structure, linear and non-linear optical properties of chalcogenides thin films, J. NonCryst. Solids, 2003, 326-327, 399-404. 
J. P. Bérubé, S. H. Messaddeq, M. Bernier, I. Skripachev, Y. Messaddeq, and R. Vallée, Tailoring the refractive index of Ge-S based glass for 3D embedded waveguides operating in the mid-IR region, Opt. Express, 2014, 22, 26103-26116.

72 R. Todorov, J. Tasseva and T. Babeva, Thin chalcogenide films for photonic applications, in Photonic Crystals - Innovative Systems, Lasers and Waveguides, ed. A. Massaro, IntechOpen, 2012, pp. 143-168.

73 A. Bytchkov, G. J. Cuello, S. Kohara, C. J. Benmore, D. L. Price, and E. Bychkov, Unraveling the atomic structure of Ge-rich sulfide glasses, Phys. Chem. Chem. Phys., 2013, 15, 8487-8494.

E. Bychkov, C. J. Benmore and D. L. Price, Compositional changes of the first sharp diffraction peak in binary selenide glasses, Phys. Rev. B: Condens. Matter Mater. Phys., 2005, 72, 172107.

M. Kassem, M. Bokova, A. Tverjanovich, D. Fontanari, D. Le Coq, A. Sokolov, P. Masselin, S. Kohara, T. Usuki, A. C. Hannon, C.J. Benmore, and E. Bychkov, Bent $\mathrm{HgI}_{2}$ molecules in the melt and sulfide glasses: Implications for nonlinear optics, Chem. Mater. 2019, 31, 4103-4112. E. Lorch, Neutron diffraction by germania, silica and radiation-damaged silica glasses, J. Phys. C: Solid State Phys. 1969, 2, 229-237.

A. Kuhn and A. Chevy, Refinement of the $2 \mathrm{H}$ GaS $\beta$-type, Acta Crystallogr., Sect. B: Struct. Crystallogr. Cryst. Chem., 1976, 32, 2060-2064.

S. Le Roux, A. Bouzid, M. Boero and C. Massobrio, Structural properties of glassy $\mathrm{Ge}_{2} \mathrm{Se}_{3}$ from firstprinciples molecular dynamics, Phys. Rev. B: Condens. Matter Mater. Phys., 2012, 86, 224201. F. Bachhuber, J. von Appen, R. Dronskowski, P. Schmidt, T. Nilges, A. Pfitzner, and R. Weihrich, The extended stability range of phosphorus allotropes, Angew. Chem. Int. Ed. 2014, 53, 11629-11633. M. Kassem, T. Bounazef, D. Fontanari, A. Sokolov, M. Bokova, A. C. Hannon, and E. Bychkov, Chemical and topological variety in sodium thioarsenate glasses studied by neutron diffraction and supported by first-principles simulations, Inorg. Chem., 2020, submitted.

81 T. Ohkubo, K. Ohara and E. Tsuchida, Conduction mechanism in $70 \mathrm{Li}_{2} \mathrm{~S}-30 \mathrm{P}_{2} \mathrm{~S}_{5}$ glass by ab initio molecular dynamics simulations: Comparison with $\mathrm{Li}_{7} \mathrm{P}_{3} \mathrm{~S}_{11}$ crystal, ACS Appl. Mater. Interfaces, 2020, 12, 25736-25747.

G. Dittmar and H. Schäfer, Die Kristallstruktur von H.T.-GeS, Acta Crystallogr., Sect. B: Struct. Crystallogr. Cryst. Chem., 1975, 31, 2060-2064.

83 S. Blaineau, P. Jund and D. A. Drabold, Physical properties of a $\mathrm{GeS}_{2}$ glass using approximate $a b$ initio molecular dynamics, Phys. Rev. B: Condens. Matter Mater. Phys., 2003, 67, 094204. G. Ori, C. Massobrio, A. Bouzid, M. Boero and B. Coasne, Surface of glassy $\mathrm{GeS}_{2}$ : A model based on a first-principles approach, Phys. Rev. B: Condens. Matter Mater. Phys., 2014, 90, 045423.

85 R. M. A. Lieth, H. J. M. Heijligers and C. W. M. Heijden, The P-T-X phase diagram of the system Ga-S, J. Electrochem. Soc., 1966, 113, 798-800.

86 M. P. Pardo, M. Guittard, A. Chilouet and A. Tomas, Diagramme de phases gallium-soufre et études structurales des phases solides, J. Solid State Chem., 1993, 102, 423-433.

87 A. Zavrazhnov, S. Berezin, A. Kosykov, A. Naumov, M. Berezina, N. Brezhnev, The phase diagram of the Ga-S system in the concentration range of 48.0-60.7 mol\% S, J. Therm. Anal. Calorimetry, 2018, 134, 483-492.

88 S. C. Moss and D. L. Price, Random packing of structural units and the first sharp diffraction peak in glasses, in Physics of Disordered Materials, ed. D. Adler, H. Fritzsche and S. R. Ovshinsky, Plenum Press, New York, 1985, pp. 77-95.

89 R. Huang, I. Chavez, K. M. Taute, B. Lukić, S. Jeney, M. G. Raizen, and E.-L. Florin, Direct observation of the full transition from ballistic to diffusive Brownian motion in a liquid, Nature Phys., 2011, 7, 576-580.

L. Berthier and G. Biroli, Theoretical perspective on the glass transition and amorphous materials, Rev. Modern Phys., 2011, 83, 587-645.

91 A. S. Tverjanovich, Temperature dependence of the viscosity of chalcogenide glass-forming melts, Glass Phys. Chem., 2003, 29, 531-535.

92 P. Koštál, J. Shánělová and J. Málek, Viscosity of chalcogenide glass-formers, Intern. Mater. Rev., 2020, 65, 63-101.

93 S. Sastry, P. G. Debenedetti and F. H. Stillinger, Signatures of distinct dynamical regimes in the energy landscape of a glass-forming liquid, Nature, 1998, 393, 554-557. 
Table of Content Graphic

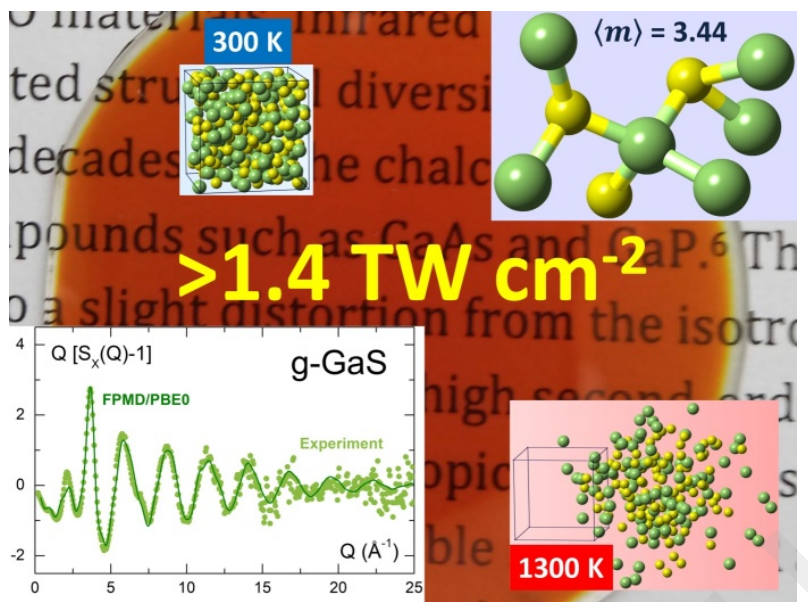

Unusually rigid glassy GaS film obtained by PLD shows excellent light-induced damage threshold promising for memory applications. 


\section{Glassy GaS: transparent and unusually rigid thin films for visible to mid-IR memory applications}

Andrey Tverjanovich, ${ }^{a}$ Maxim Khomenko, ${ }^{b}$ Sergei Bereznev, ${ }^{c}$ Daniele Fontanari, ${ }^{d}$ Anton Sokolov, ${ }^{b, d}$ Takeshi Usuki, ${ }^{e}$ Koji Ohara,$f$ David Le Coq,${ }^{g}$ Pascal Masselin, ${ }^{d}$ and Eugene Bychkov ${ }^{b, d *}$

a Institute of Chemistry, St. Petersburg State University, 198504 St. Petersburg, Russia

${ }^{b}$ ILIT RAS - Branch of the FSRC 'Crystallography and Photonics' RAS, 140700 Shatura, Moscow Region, Russia

c Department of Materials and Environmental Technology, Tallinn University of Technology, 19086 Tallinn, Estonia

${ }^{d}$ Laboratoire de Physico-Chimie de l'Atmosphère, Université du Littoral Côte d'Opale, 59140 Dunkerque, France

${ }^{e}$ Faculty of Science, Yamagata University, Yamagata 990-8560, Japan

$f$ Diffraction and Scattering Division, Japan Synchrotron Radiation Research Institute, Sayo-gun, Hyogo 6795198, Japan

${ }^{g}$ Institut des Sciences Chimiques de Rennes, Université Rennes, 35000 Rennes, France

\section{Electronic Supplementary Information}

Fig. S1. High-energy X-ray diffraction measurements at SPring-8 (Hyogo Prefecture, Japan).

Fig. S2. Experimental and simulated FPMD/PBEsol X-ray pair-distribution functions $g_{\mathrm{X}}(r)$ of glassy GaS.

Fig. S3. Mean-square displacements $\left\langle r^{2}(t)\right\rangle$ of Ga and S species as a function of FPMD time $t$ and temperature $T$. 


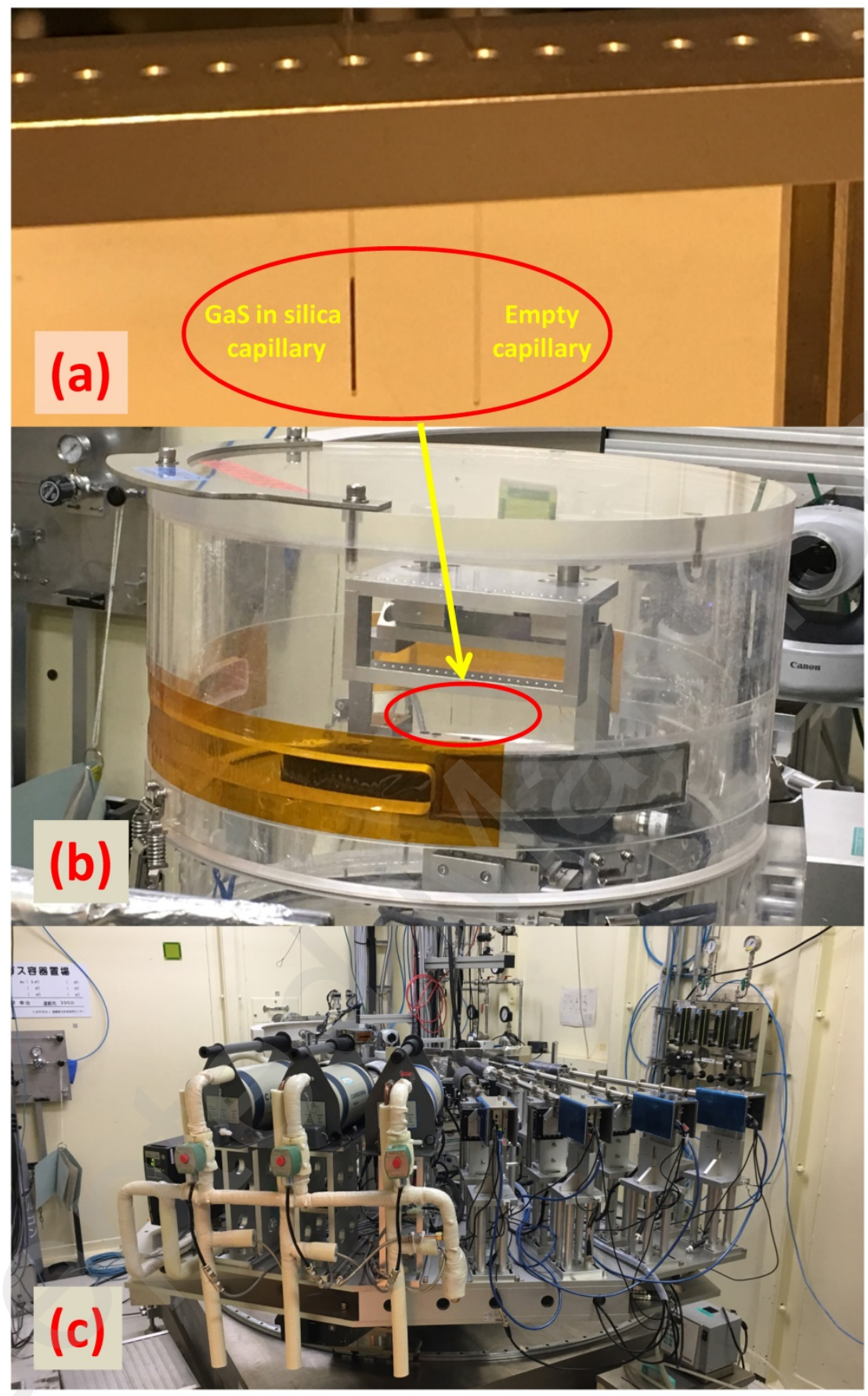

Fig. S1. High-energy X-ray diffraction measurements at SPring-8 (Hyogo Prefecture, Japan): (a) glassy GaS in thin-walled silica capillary and empty capillary for background subtraction, (b) a vacuum chamber of the dedicated two-axis BL04B2 diffractometer, (c) a 7-detector setup of BL04B2 including four cadmium telluride detectors at low angles and three Ge diodes at high diffraction angles. 


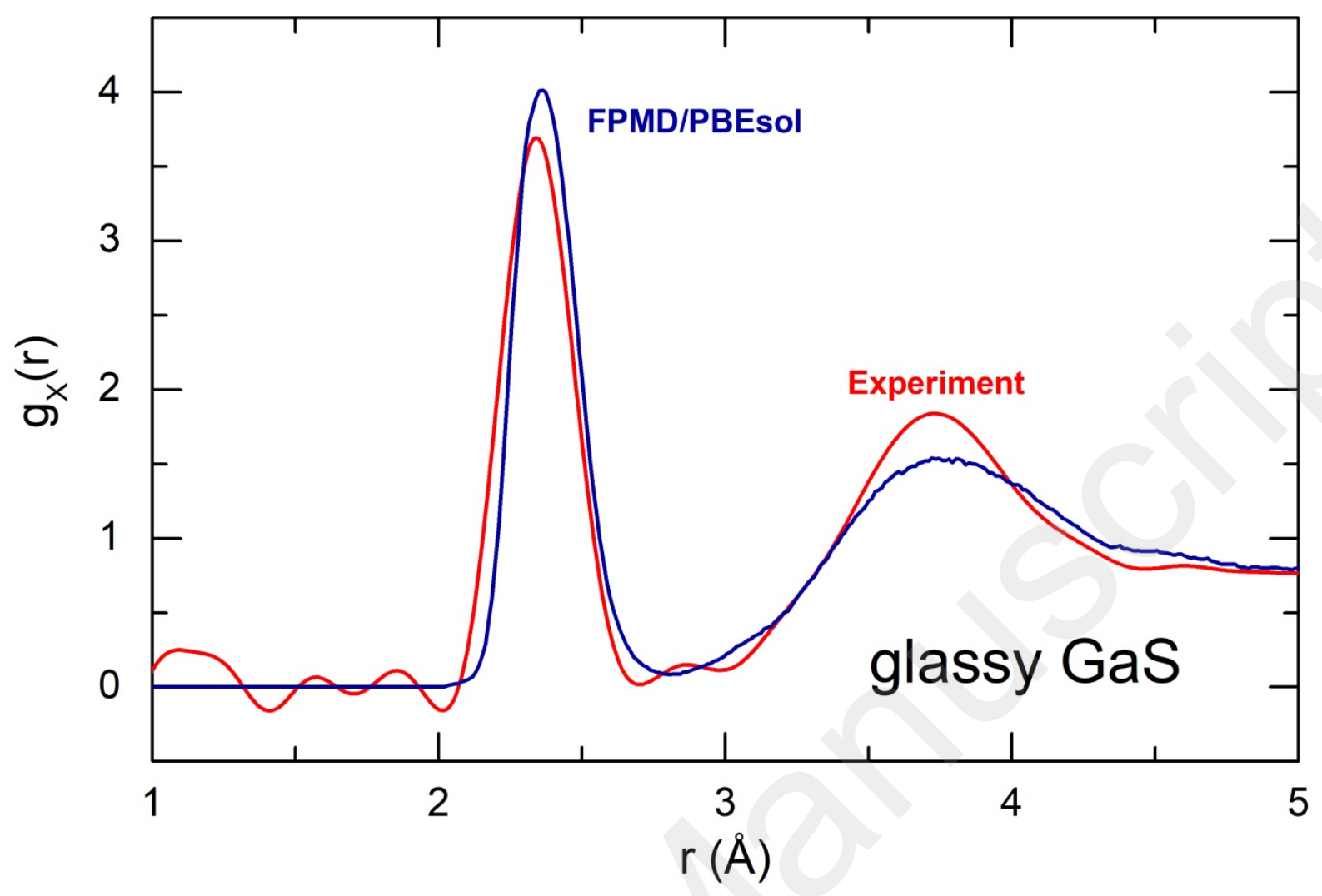

Fig. S2. Experimental (red) and simulated FPMD/PBEsol (blue) X-ray pair-distribution functions $g_{\mathrm{X}}(r)$ of glassy GaS. A typical problem of FPMD simulations using the general gradient approximation with classical PBEsol exchange-correlation functional resides in overestimation of the nearest neighbor interatomic distances resulting in a higher-r shift of the NN peak. 


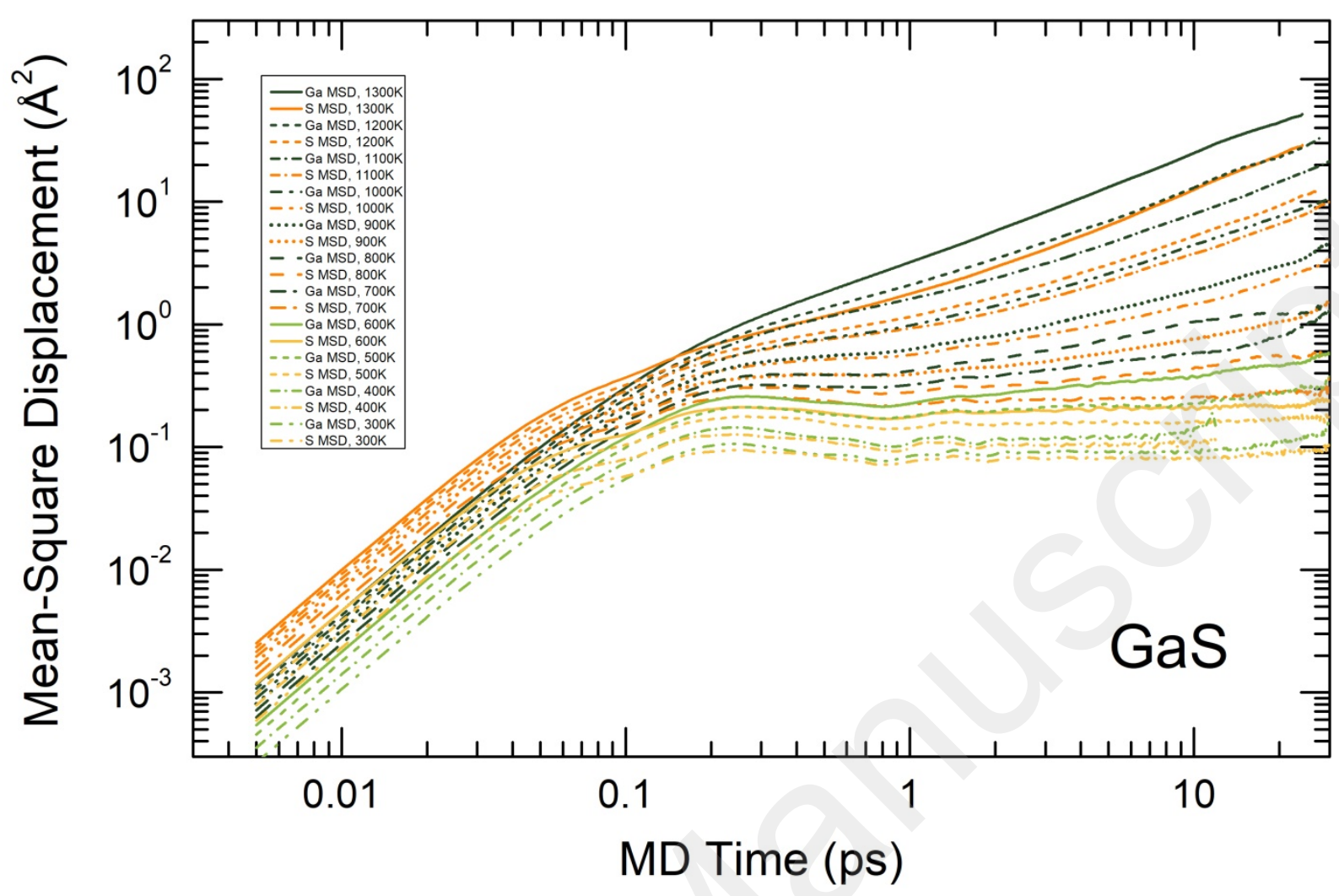

Fig. S3. Mean-square displacements $\left\langle r^{2}(t)\right\rangle$ of Ga and S species as a function of FPMD time $t$ and temperature $T$. Three characteristic regimes are clearly seen: (1) the ballistic regime below $t \lesssim 30 \mathrm{fs}$, $\left\langle r^{2}(t)\right\rangle \propto t^{2}$, (2) the intermediate regime related to vibrations and local diffusion, $\left\langle r^{2}(t)\right\rangle \propto t^{s}$, where $0 \leq s$ $<1$, and (3) the long-range diffusion motion at high $T$ and $t,\left\langle r^{2}(t)\right\rangle \propto t^{1}$. 